Supporting Information for:

\title{
Decomposition of Ruthenium Olefin Metathesis
}

\section{Catalysts}

Soon Hyeok Hong, Anna G. Wenzel, ${ }^{\dagger}$ Tina T. Salguero, ${ }^{*}$ Michael W. Day and Robert H. Grubbs*

The Arnold and Mabel Beckman Laboratory of Chemical Synthesis, Division of Chemistry and Chemical Engineering, California Institute of Technology, Pasadena, California 91125

${ }^{\dagger}$ Current Address: Joint Science Department; Claremont McKenna, Pitzer and Scripps Colleges; Claremont, California 91711.

${ }^{\ddagger}$ Current Address: HRL Laboratories, LLC; Malibu, California 90265-4797. 
Chart S.1. Decomposition of 5.
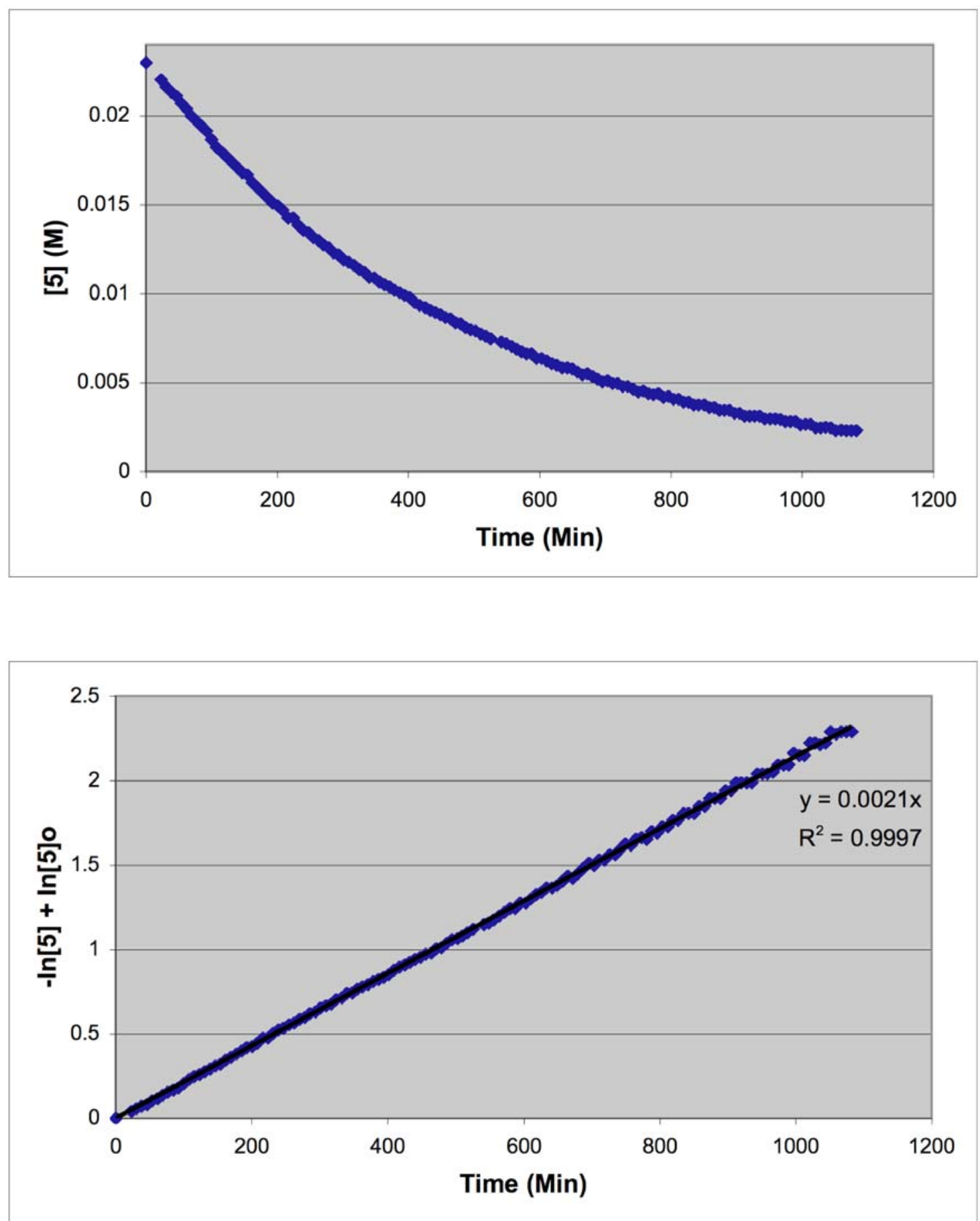
Chart S.2. Decomposition of 14 .
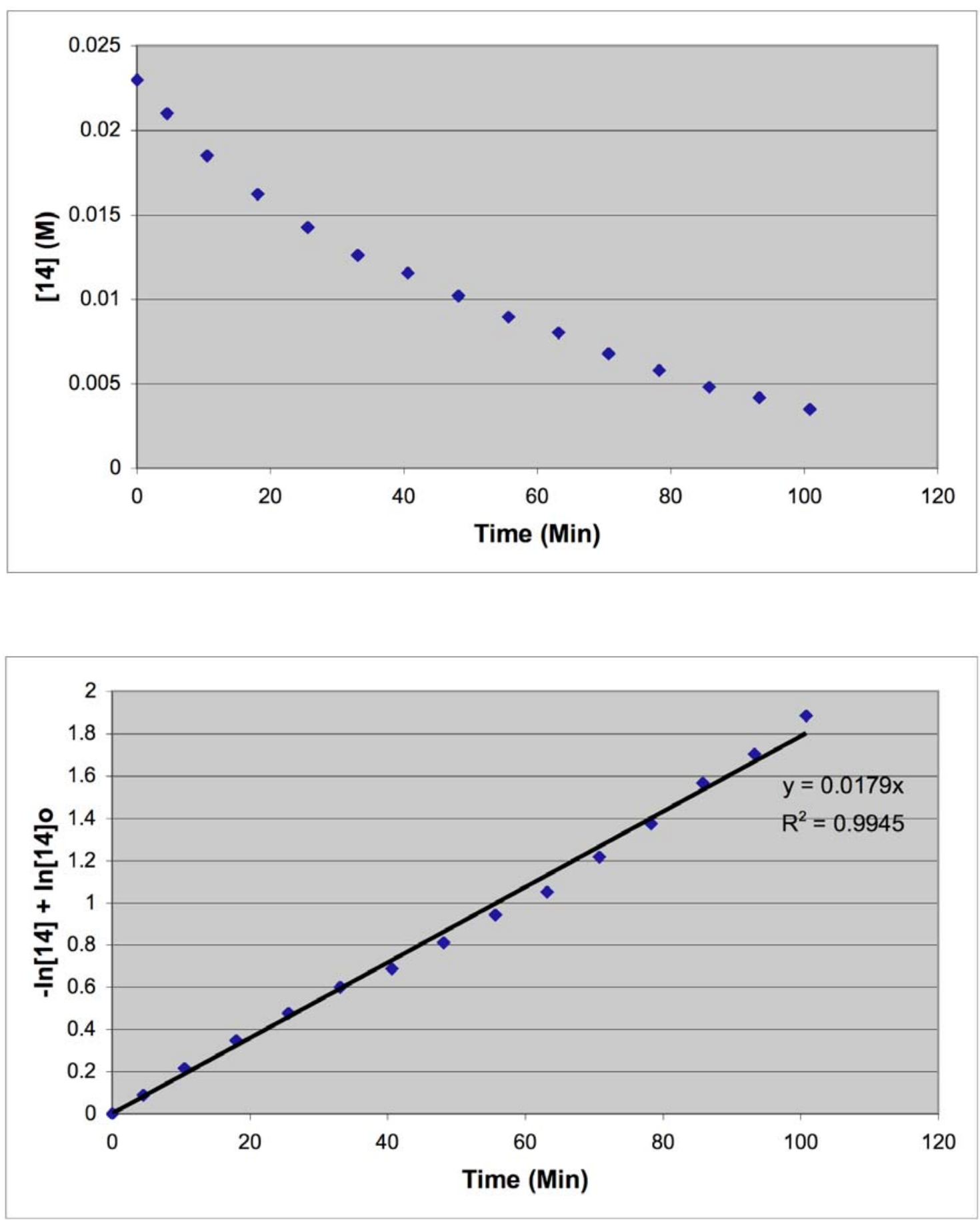
Chart S.3. Decomposition of $\mathbf{1 6}$.
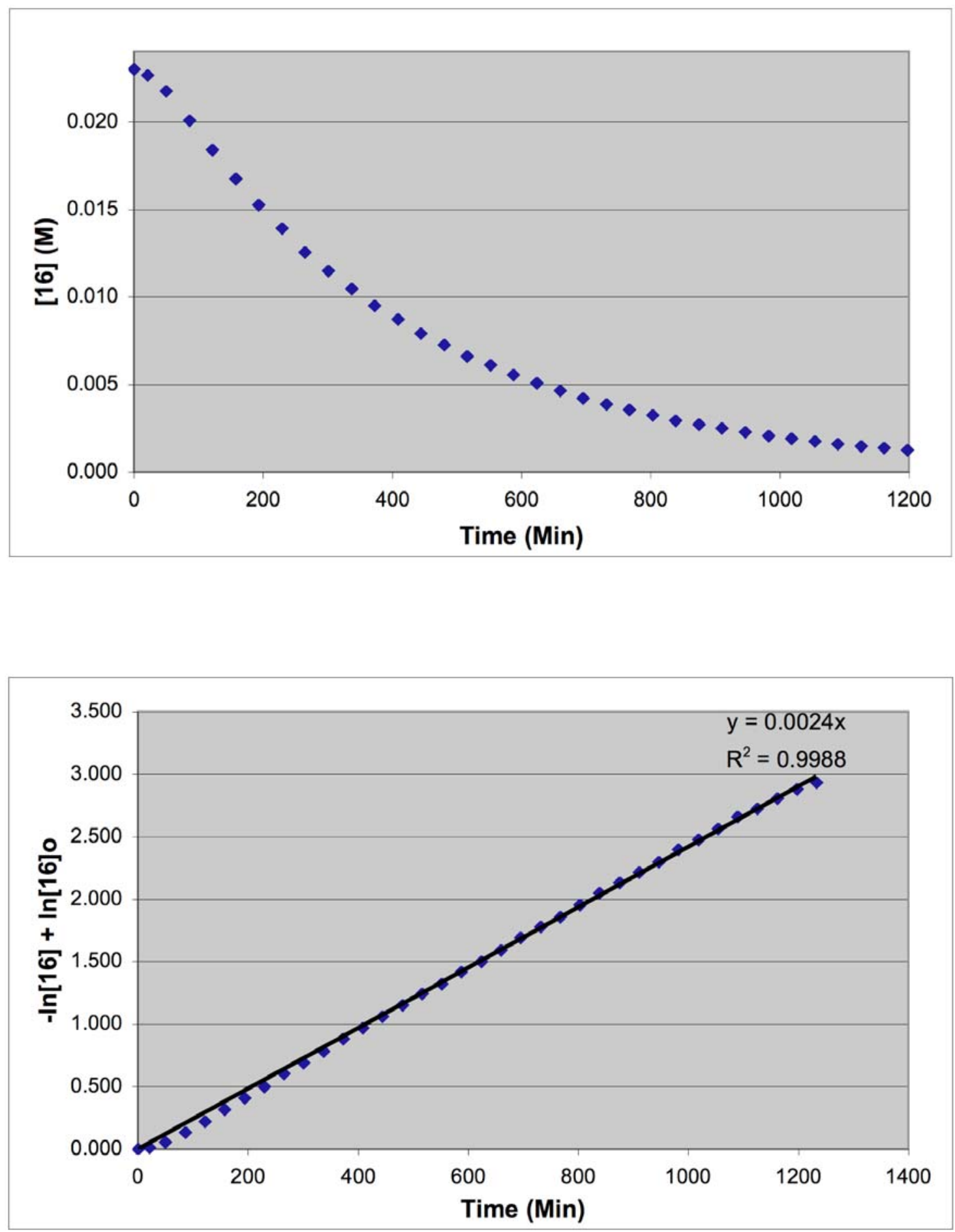
Chart S.4. Decomposition of 17.
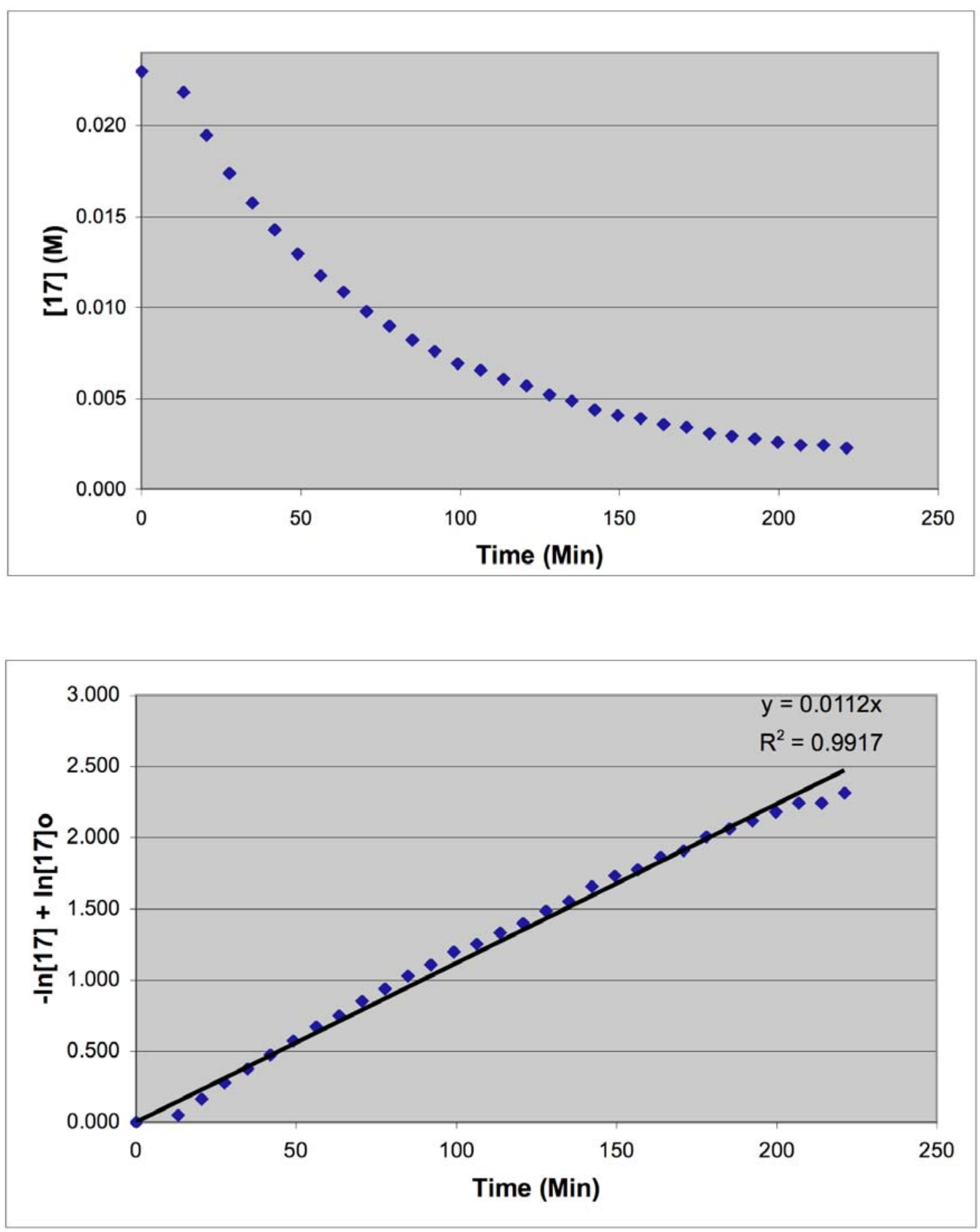
Chart S.5. Decomposition reaction of $\mathbf{1 8}$ with ethylene.

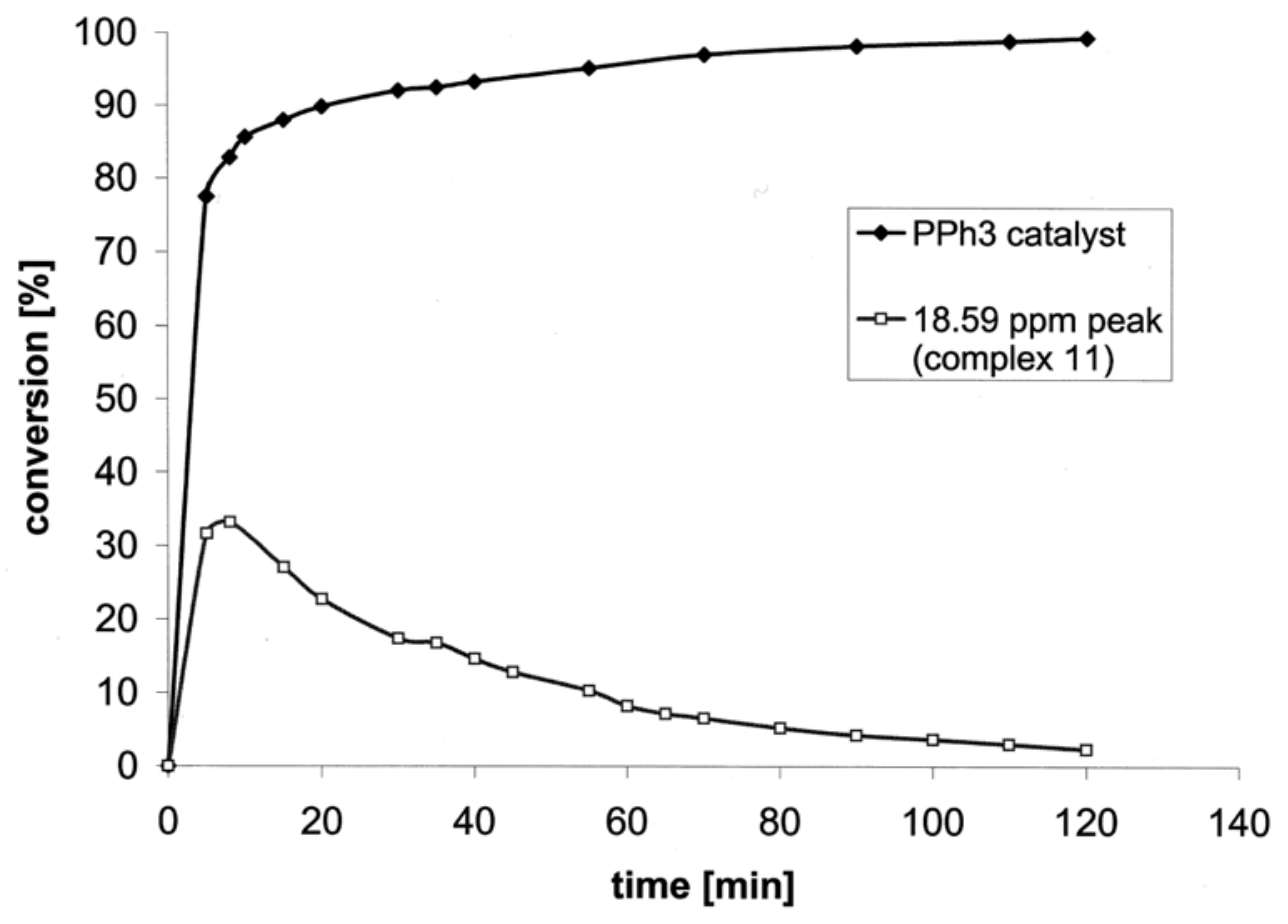


Figure S.1. ${ }^{31}$ P NMR Spectrum after Decomposition of 5.

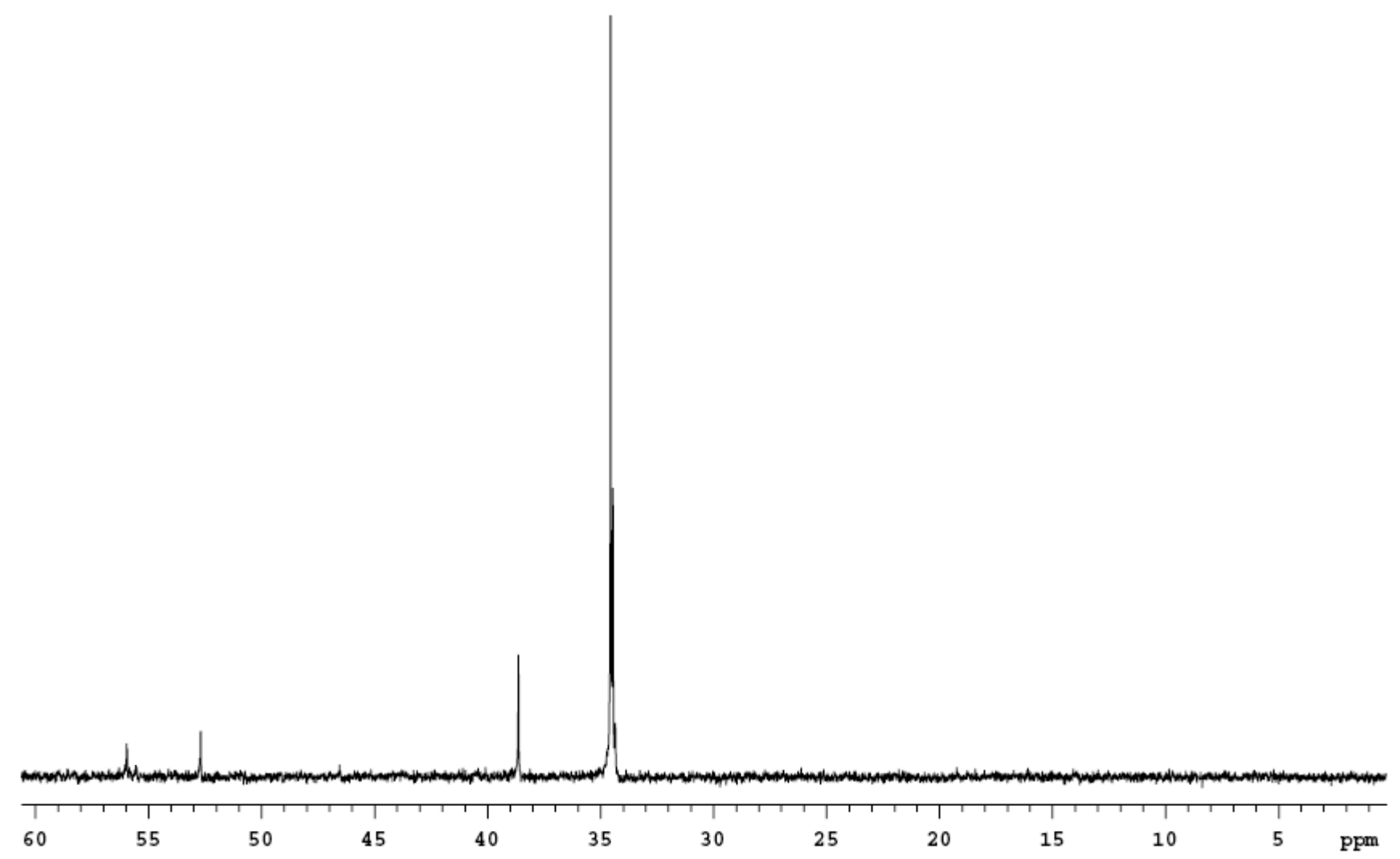

Figure S.2. ${ }^{31} \mathrm{P}$ NMR Spectrum after Decomposition of $\mathbf{1 3}$.

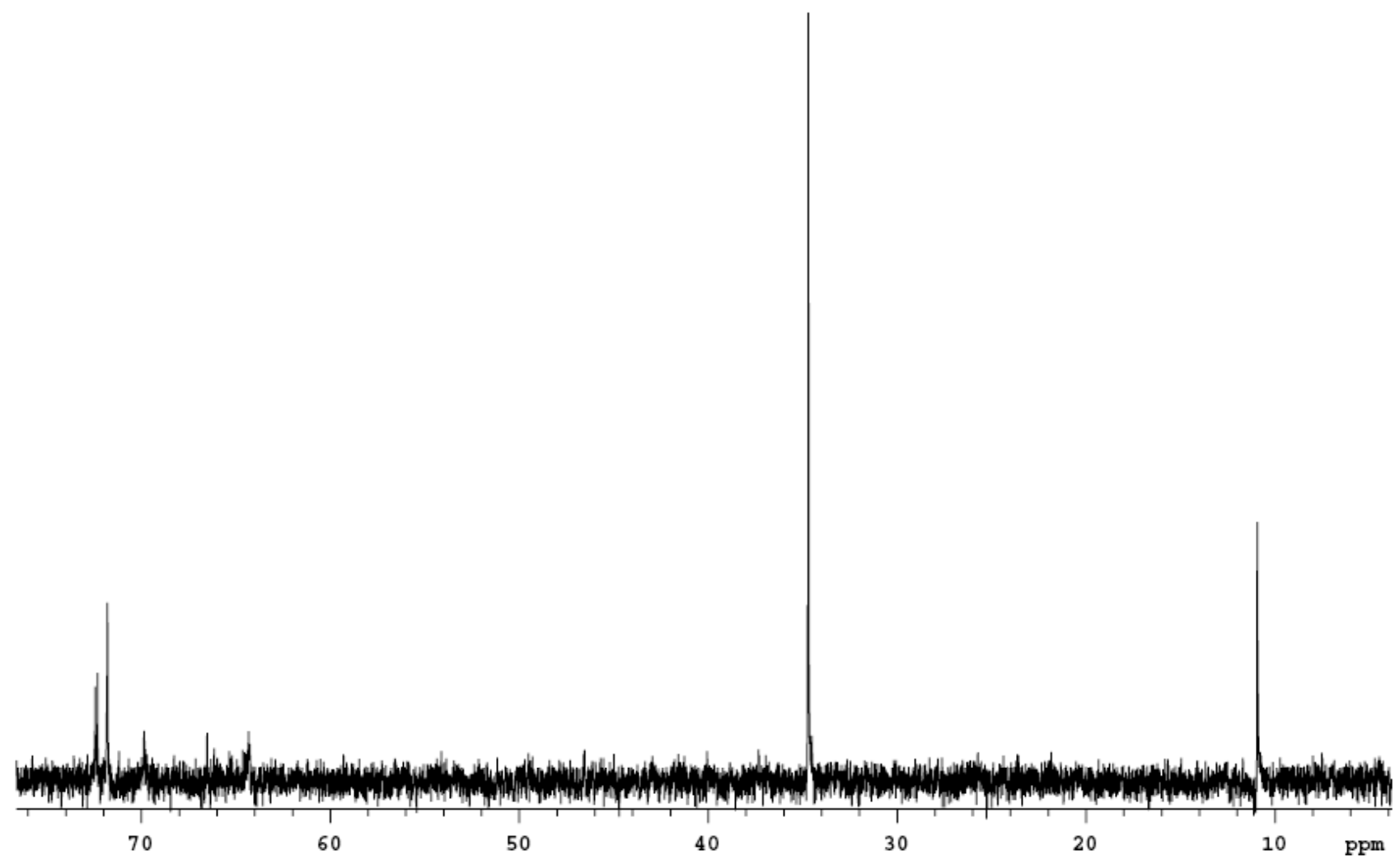


Figure S.3. ${ }^{31}$ P NMR Spectrum after Decomposition of $\mathbf{1 4}$.

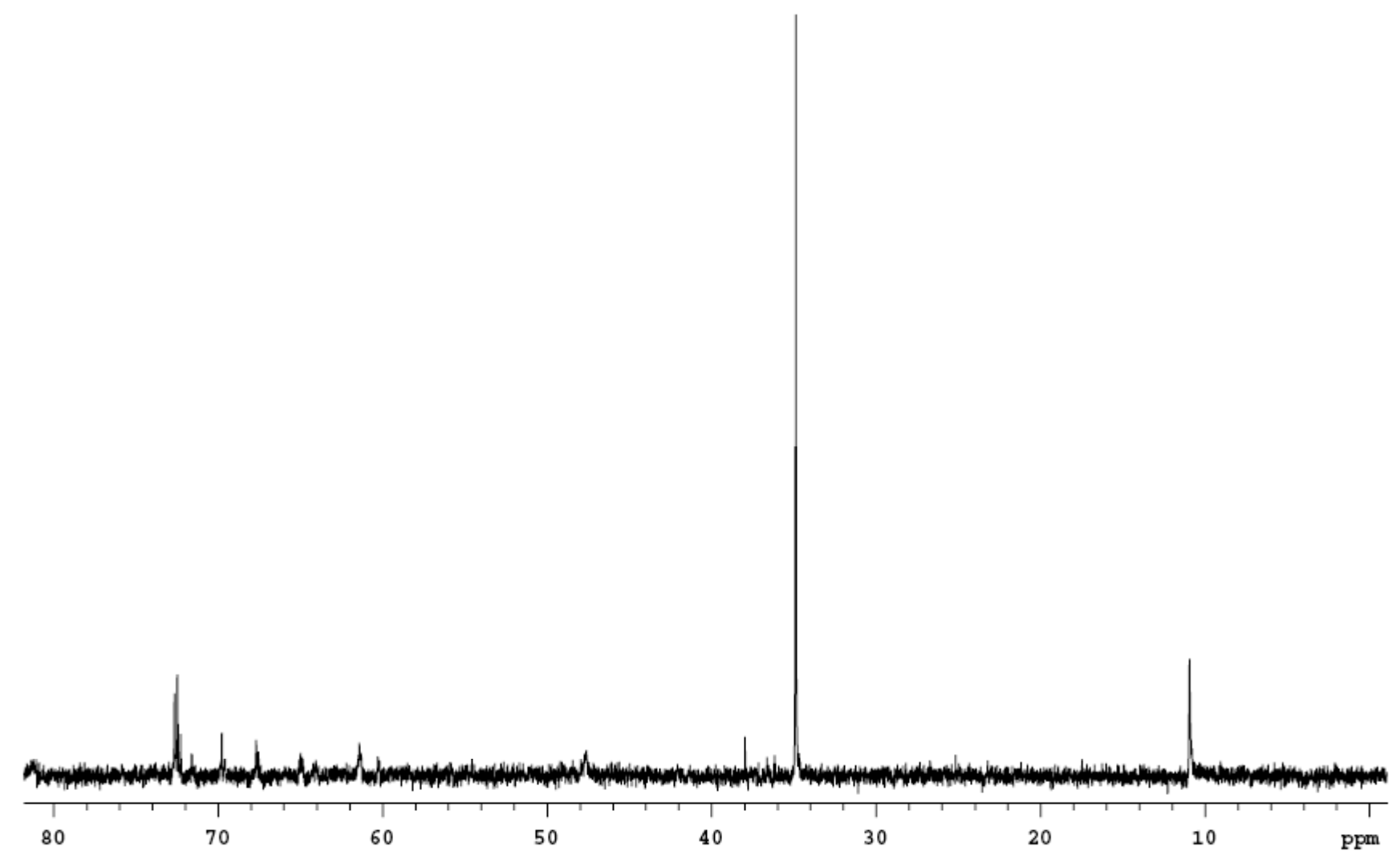

Figure S.4. ${ }^{31}$ P NMR Spectrum after Decomposition of $\mathbf{1 6 .}$

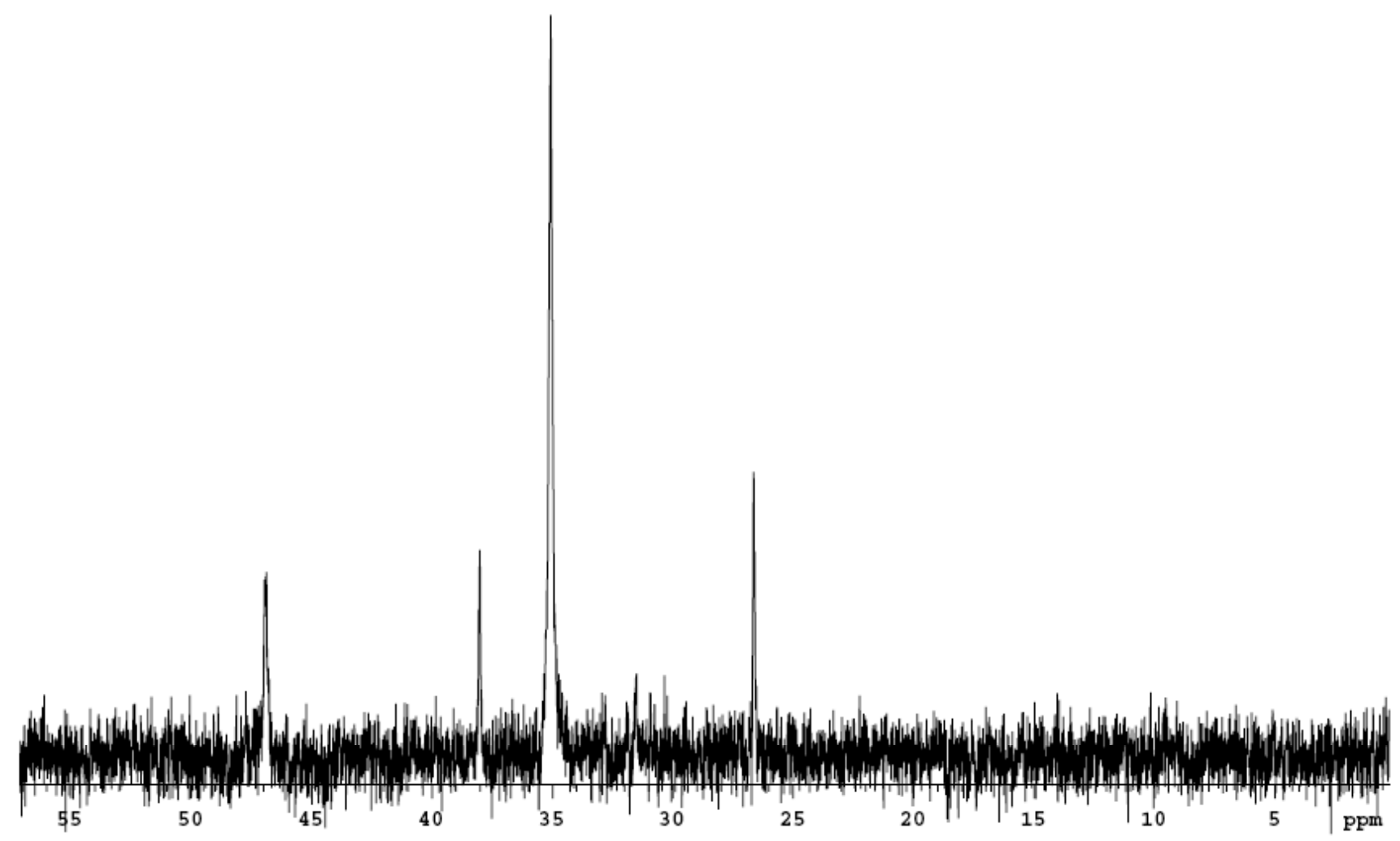


Figure S.5. ${ }^{31} \mathrm{P}$ NMR Spectrum after Decomposition of $\mathbf{1 7 .}$

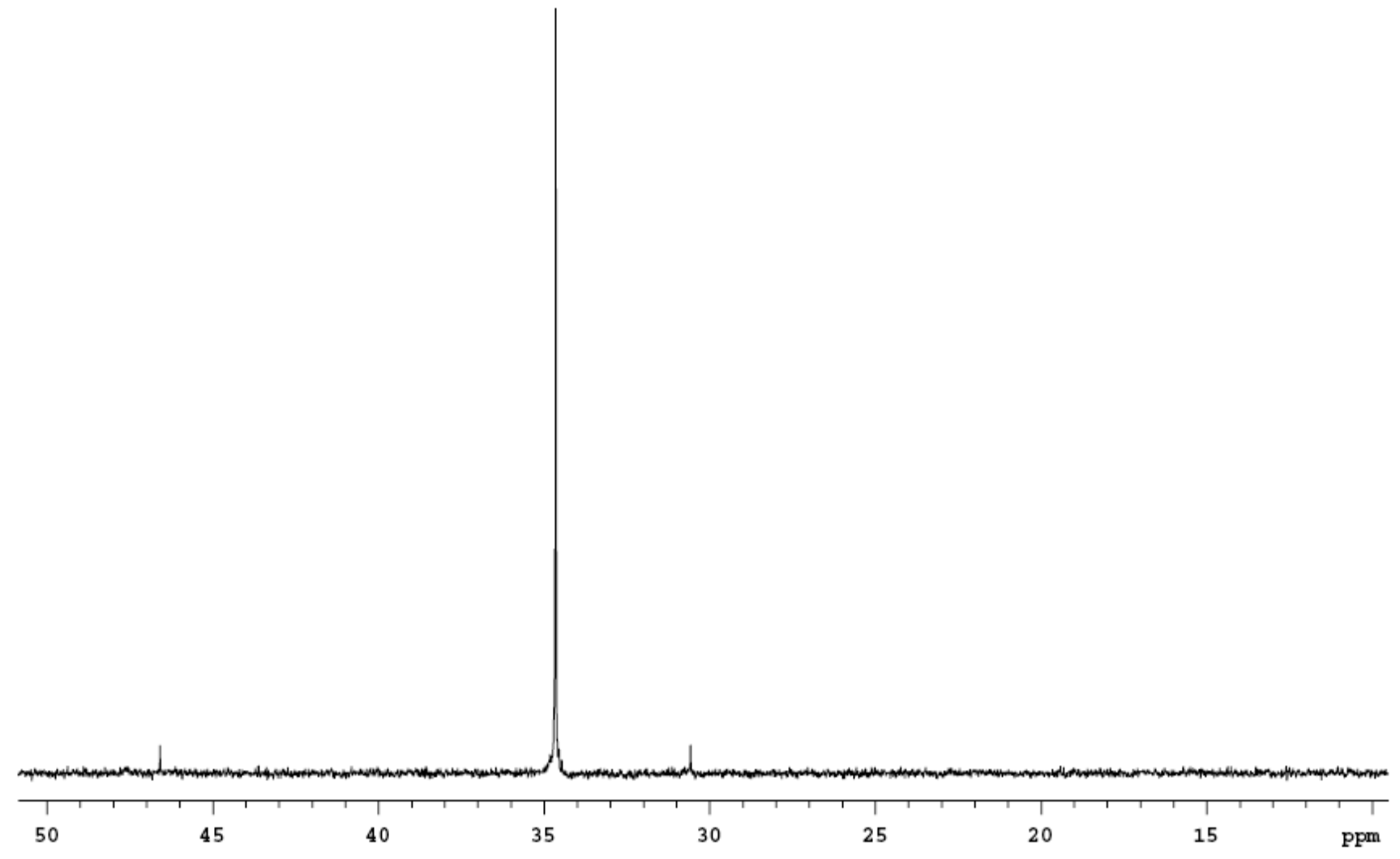

Figure S.6. Mass spectrometric analysis of the reaction of 18 with ethylene after 8 min at $23{ }^{\circ} \mathrm{C}$.

Instrument: JEOL MSRoute Ionization mode: FAB+ RHG

Scan: $1-20 *$

Base: $\mathbf{m} / \mathbf{z}$ 704; 15.1\%FS

TIC: 6129890

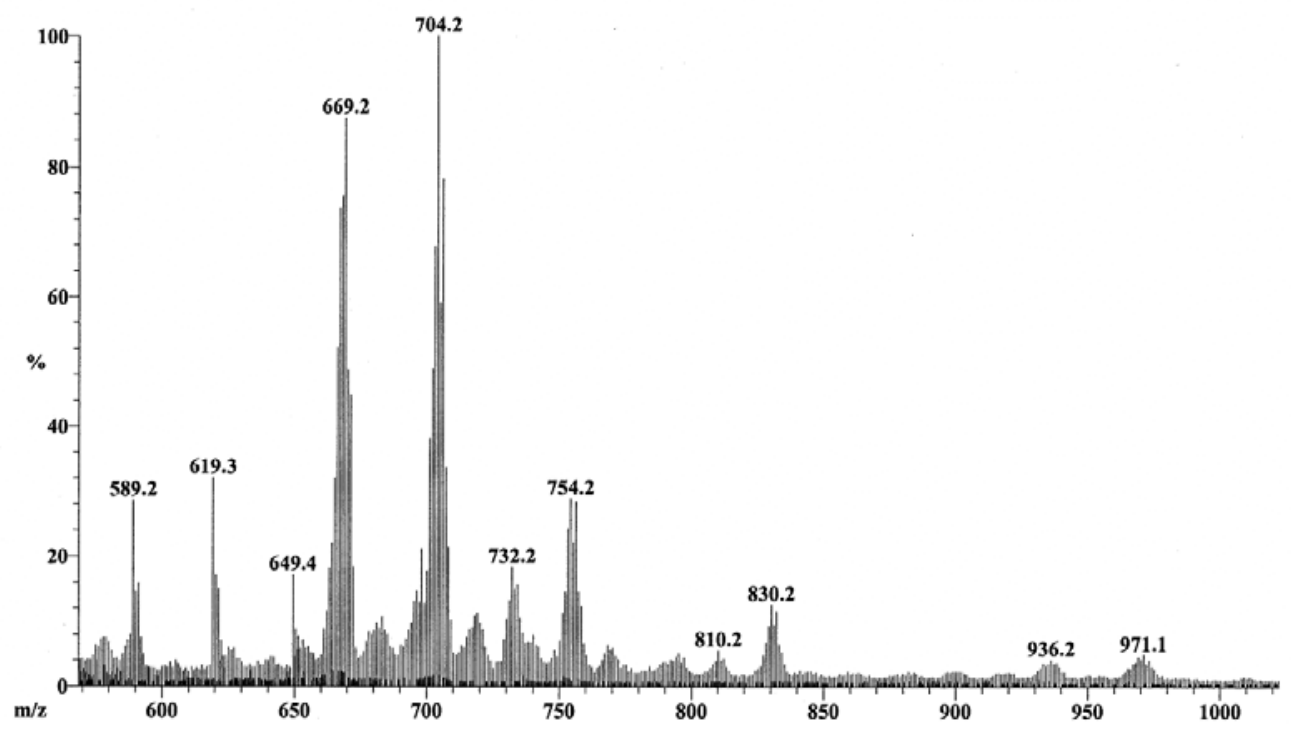


Figure S.7. ${ }^{31} \mathrm{P}$ NMR of the reaction of $\mathbf{1 8}$ with ethylene after $24 \mathrm{~h}$.
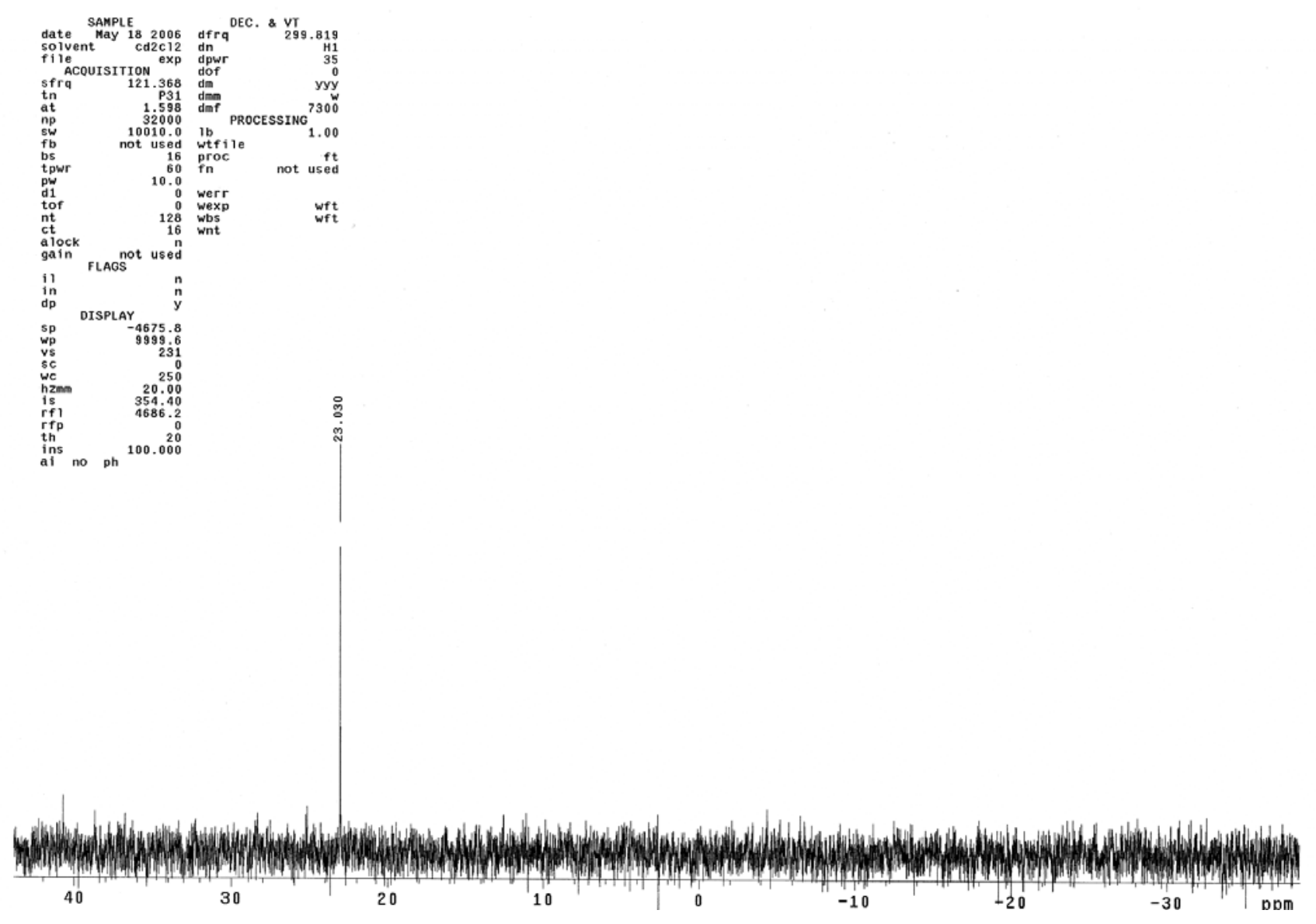


\title{
Crystal Structure Analysis of 7
}

\author{
Contents
}

Table S.1. Crystal data

Figures Figures

Table S.2. Atomic Coordinates

Table S.3. Full bond distances and angles

Table S.4. Anisotropic displacement parameters

Table S.5. Hydrogen atomic coordinates

Table S.6. Hydrogen bond distances and angles

Table S.7. Observed and calculated structure factors (available upon request)

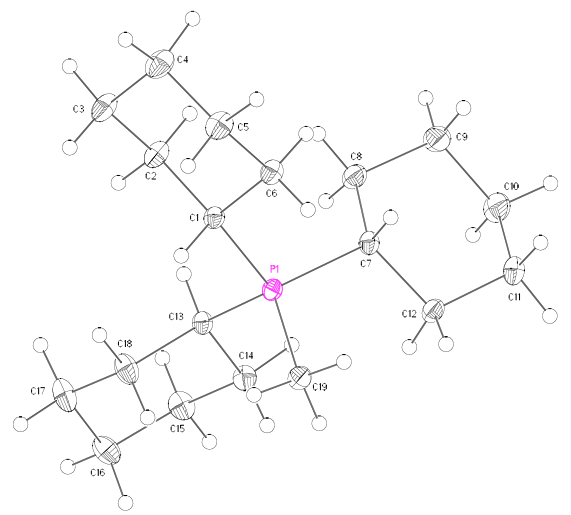

Note: Crystallographic data have been deposited at the CCDC, 12 Union Road, Cambridge CB2 1EZ, UK and copies can be obtained on request, free of charge, by quoting the publication citation and the deposition number 288113. 
Table S.1. Crystal data and structure refinement for 7 (CCDC 288113).

Empirical formula

Formula weight

Crystallization Solvent

Crystal Habit

Crystal size

Crystal color

Type of diffractometer

Wavelength

Data Collection Temperature

$\theta$ range for 8830 reflections used in lattice determination

Unit cell dimensions

Volume

$\mathrm{Z}$

Crystal system

Space group

Density (calculated)

$\mathrm{F}(000)$

Data collection program

$\theta$ range for data collection

Completeness to $\theta=35.91^{\circ}$

Index ranges

Data collection scan type

Data reduction program

Reflections collected

Independent reflections

Absorption coefficient

Absorption correction

Max. and min. transmission
$\left[\mathrm{C}_{19} \mathrm{H}_{36} \mathrm{P}\right]^{+} \mathrm{Cl}^{-} \bullet 3\left(\mathrm{H}_{2} \mathrm{O}\right)$

384.95

Water

Block

$0.30 \times 0.23 \times 0.18 \mathrm{~mm}^{3}$

Colorless

\section{Data Collection}

Bruker SMART 1000

$0.71073 \AA$ AoK $\alpha$

100(2) K

2.47 to $35.53^{\circ}$

$\mathrm{a}=9.8774(4) \AA$

$\mathrm{b}=10.0035(5) \AA$

$\alpha=85.1580(10)^{\circ}$

$\mathrm{c}=12.7700(6) \AA$

$\beta=74.3040(10)^{\circ}$

$\gamma=63.5350(10)^{\circ}$

1086.48(9) $\AA^{3}$

2

Triclinic

P-1

$1.177 \mathrm{Mg} / \mathrm{m}^{3}$

424

Bruker SMART v5.630

1.66 to $35.91^{\circ}$

$79.6 \%$

$-15 \leq \mathrm{h} \leq 16,-15 \leq \mathrm{k} \leq 15,-18 \leq 1 \leq 16$

$\omega$ scans at $5 \phi$ settings

Bruker SAINT v6.45A

19055

$8153\left[\mathrm{R}_{\mathrm{int}}=0.0545\right]$

$0.263 \mathrm{~mm}^{-1}$

None

0.9541 and 0.9252 


\section{Table S.1 (cont.)}

\section{Structure solution and Refinement}

Structure solution program

Primary solution method

Secondary solution method

Hydrogen placement

Structure refinement program

Refinement method

Data / restraints / parameters

Treatment of hydrogen atoms

Goodness-of-fit on $\mathrm{F}^{2}$

Final $R$ indices [I $>2 \sigma(\mathrm{I}), 5822$ reflections]

$\mathrm{R}$ indices (all data)

Type of weighting scheme used

Weighting scheme used

Max shift/error

Average shift/error

Largest diff. peak and hole
Bruker XS v6.12

Direct methods

Difference Fourier map

Difference Fourier map

Bruker XL v6.12

Full matrix least-squares on $\mathrm{F}^{2}$

8153 / 0 / 361

Mixed

1.307

$\mathrm{R} 1=0.0383, w \mathrm{R} 2=0.0724$

$\mathrm{R} 1=0.0618, w \mathrm{R} 2=0.0772$

Sigma

$w=1 / \sigma^{2}\left(\mathrm{Fo}^{2}\right)$

0.001

0.000

0.506 and -0.365 e. $\AA^{-3}$

\section{Special Refinement Details}

The extended structure contains a network of hydrogen bonds between water and chloride (see Table 6). The orientations of $\mathrm{O}(1)$ and $\mathrm{O}(3)$ alternate between two possible orientations in the network and therefore each have one hydrogen atom $\{\mathrm{H}(1 \mathrm{AA})$ and $\mathrm{H}(3 \mathrm{AA})\}$ in a fully occupied site; the other sites were modeled with 50:50 occupancy. Additionally, Table 6 lists donor-acceptor interactions of hydrogens bonded to C(19).

All hydrogen atoms were located in the electron difference Fourier map. Hydrogen atoms on water were restrained to ride the respective oxygen atom with the isotropic temperature factor set to 1.2 times that of the oxygen. All other hydrogen atoms were refined without restraints.

Refinement of $\mathrm{F}^{2}$ against ALL reflections. The weighted R-factor $(w \mathrm{R})$ and goodness of fit $(\mathrm{S})$ are based on $\mathrm{F}^{2}$, conventional R-factors $(R)$ are based on $F$, with $F$ set to zero for negative $F^{2}$. The threshold expression of $F^{2}>2 \sigma\left(F^{2}\right)$ is used only for calculating R-factors $(\mathrm{gt})$ etc. and is not relevant to the choice of reflections for refinement. R-factors based on $\mathrm{F}^{2}$ are statistically about twice as large as those based on F, and R-factors based on ALL data will be even larger.

All esds (except the esd in the dihedral angle between two l.s. planes) are estimated using the full covariance matrix. The cell esds are taken into account individually in the estimation of esds in distances, angles and torsion angles; correlations between esds in cell parameters are only used when they are defined by crystal symmetry. An approximate (isotropic) treatment of cell esds is used for estimating esds involving 1.s. planes. 


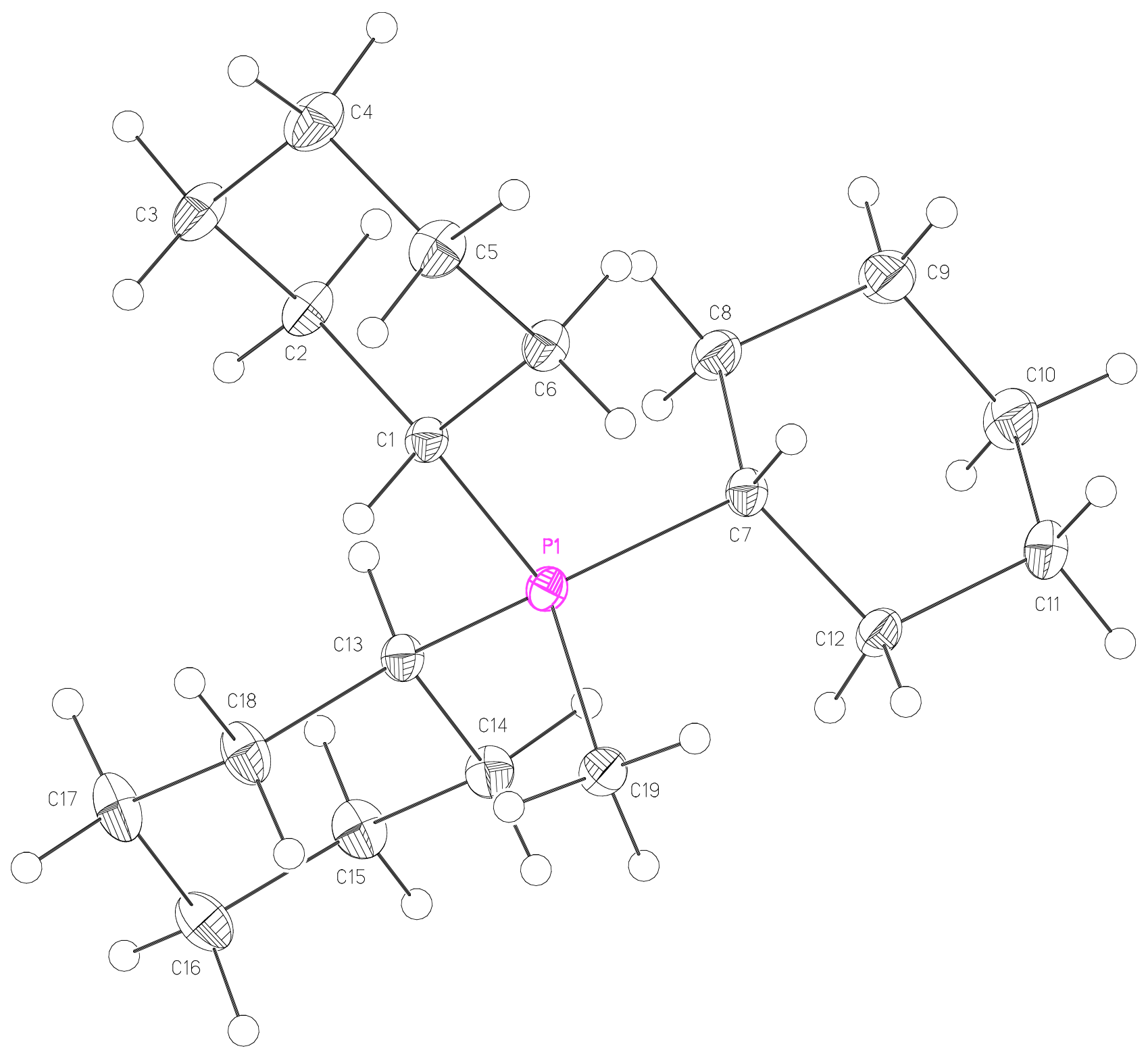



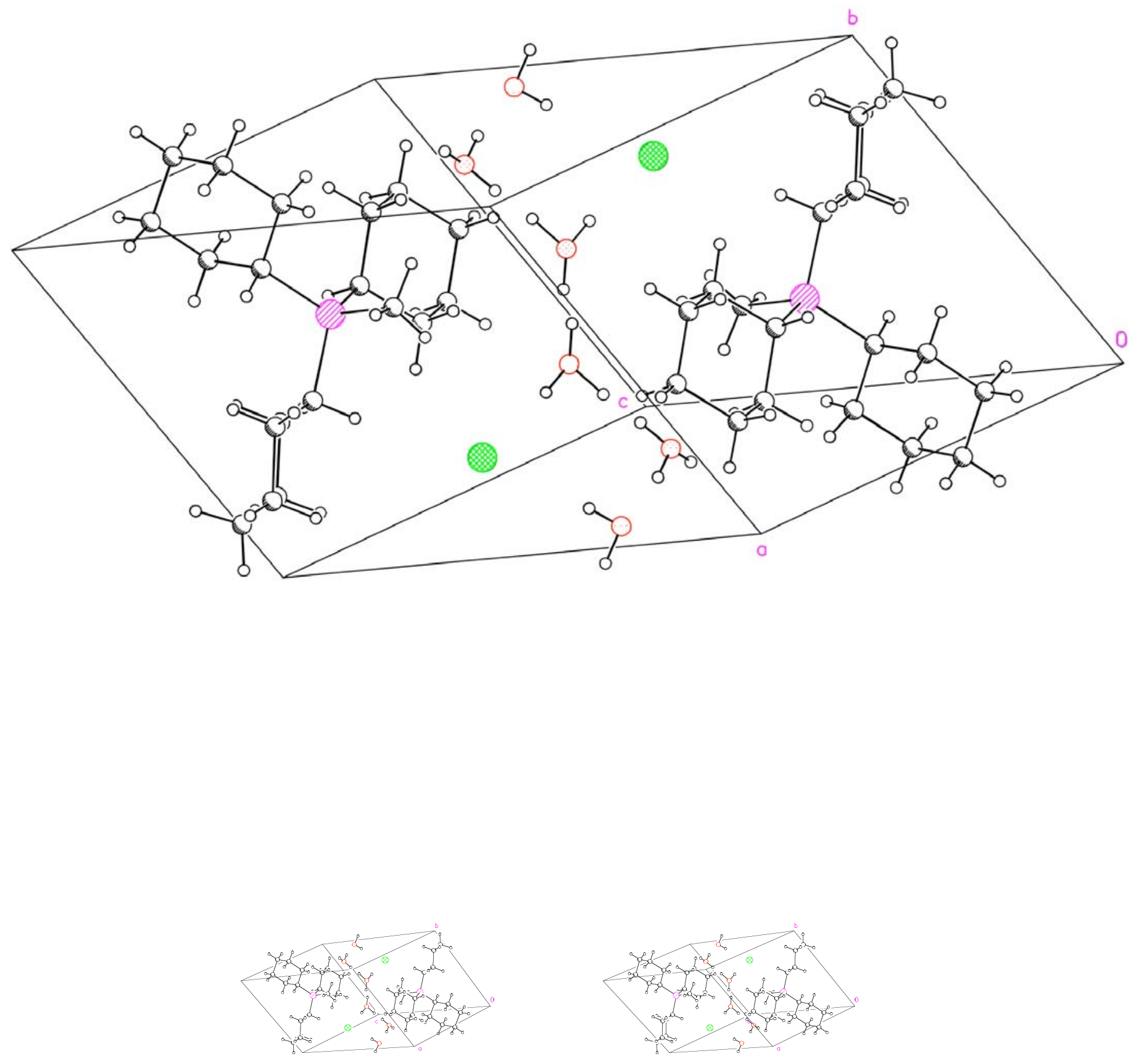
Table S.2. Atomic coordinates $\left(x 1^{4}\right)$ and equivalent isotropic displacement parameters $\left(\AA^{2} x\right.$ $10^{3}$ ) for 7 (CCDC 288113). $U(e q)$ is defined as the trace of the orthogonalized $U^{i j}$ tensor.

\begin{tabular}{|c|c|c|c|c|}
\hline & $\mathrm{X}$ & $\mathrm{y}$ & $\mathrm{z}$ & $\mathrm{U}_{\mathrm{eq}}$ \\
\hline $\mathrm{Cl}(1)$ & $843(1)$ & $7434(1)$ & 4983(1) & $23(1)$ \\
\hline $\mathrm{P}(1)$ & $7499(1)$ & $6374(1)$ & $7287(1)$ & 11(1) \\
\hline $\mathrm{C}(1)$ & $9079(1)$ & $4584(1)$ & $7476(1)$ & $12(1)$ \\
\hline $\mathrm{C}(2)$ & 8913(1) & $3984(1)$ & $8628(1)$ & $17(1)$ \\
\hline $\mathrm{C}(3)$ & $10209(1)$ & 2394(1) & $8609(1)$ & $19(1)$ \\
\hline $\mathrm{C}(4)$ & $11836(1)$ & $2337(1)$ & $8142(1)$ & $21(1)$ \\
\hline $\mathrm{C}(5)$ & $11995(1)$ & 2983(1) & $7018(1)$ & $18(1)$ \\
\hline$C(6)$ & $10698(1)$ & $4575(1)$ & $7041(1)$ & $15(1)$ \\
\hline $\mathrm{C}(7)$ & $7758(1)$ & $7956(1)$ & $7647(1)$ & $13(1)$ \\
\hline $\mathrm{C}(8)$ & $7413(1)$ & 8199(1) & $8878(1)$ & $17(1)$ \\
\hline $\mathrm{C}(9)$ & $7652(2)$ & $9531(1)$ & $9144(1)$ & $22(1)$ \\
\hline$C(10)$ & $6667(2)$ & $10945(1)$ & $8629(1)$ & $22(1)$ \\
\hline $\mathrm{C}(11)$ & $7072(1)$ & $10711(1)$ & $7403(1)$ & $18(1)$ \\
\hline $\mathrm{C}(12)$ & $6845(1)$ & 9395(1) & $7094(1)$ & $15(1)$ \\
\hline$C(13)$ & $5645(1)$ & $6391(1)$ & $8075(1)$ & $13(1)$ \\
\hline$C(14)$ & $4202(1)$ & $7885(1)$ & $8081(1)$ & $15(1)$ \\
\hline$C(15)$ & 2691(1) & $7796(1)$ & $8726(1)$ & $18(1)$ \\
\hline$C(16)$ & $2525(1)$ & $6513(1)$ & $8300(1)$ & $21(1)$ \\
\hline $\mathrm{C}(17)$ & $3952(1)$ & $5035(1)$ & $8306(1)$ & $22(1)$ \\
\hline $\mathrm{C}(18)$ & $5457(1)$ & $5103(1)$ & $7643(1)$ & $19(1)$ \\
\hline$C(19)$ & $7583(1)$ & $6440(1)$ & $5871(1)$ & $15(1)$ \\
\hline $\mathrm{O}(1)$ & $4337(1)$ & $9038(1)$ & $5373(1)$ & $26(1)$ \\
\hline $\mathrm{O}(2)$ & $1175(1)$ & $9878(1)$ & $6256(1)$ & $28(1)$ \\
\hline $\mathrm{O}(3)$ & $5521(1)$ & $3560(1)$ & $5392(1)$ & $30(1)$ \\
\hline
\end{tabular}


Table S.3. Bond lengths $[\AA]$ and angles $\left[{ }^{\circ}\right]$ for 7 (CCDC 288113).

\begin{tabular}{|c|c|c|c|}
\hline $\mathrm{P}(1)-\mathrm{C}(19)$ & $1.7847(12)$ & $\mathrm{C}(16)-\mathrm{H}(16 \mathrm{~A})$ & $0.985(14)$ \\
\hline $\mathrm{P}(1)-\mathrm{C}(7)$ & $1.8254(10)$ & $\mathrm{C}(16)-\mathrm{H}(16 \mathrm{~B})$ & $0.952(14)$ \\
\hline $\mathrm{P}(1)-\mathrm{C}(13)$ & $1.8279(10)$ & $\mathrm{C}(17)-\mathrm{C}(18)$ & $1.5270(16)$ \\
\hline $\mathrm{P}(1)-\mathrm{C}(1)$ & $1.8280(10)$ & $\mathrm{C}(17)-\mathrm{H}(17 \mathrm{~A})$ & $0.993(14)$ \\
\hline $\mathrm{O}(1)-\mathrm{H}(1 \mathrm{AA})$ & 0.8600 & $\mathrm{C}(17)-\mathrm{H}(17 \mathrm{~B})$ & $0.934(15)$ \\
\hline $\mathrm{O}(1)-\mathrm{H}(1 \mathrm{BA})$ & 0.8444 & $\mathrm{C}(18)-\mathrm{H}(18 \mathrm{~A})$ & $0.937(14)$ \\
\hline $\mathrm{O}(1)-\mathrm{H}(1 \mathrm{BB})$ & 0.8432 & $\mathrm{C}(18)-\mathrm{H}(18 \mathrm{~B})$ & $0.970(13)$ \\
\hline $\mathrm{O}(2)-\mathrm{H}(2 \mathrm{AA})$ & 0.7801 & C(19)-H(19A) & $0.959(14)$ \\
\hline $\mathrm{O}(2)-\mathrm{H}(2 \mathrm{BA})$ & 0.8992 & C(19)-H(19B) & $0.978(13)$ \\
\hline $\mathrm{O}(3)-\mathrm{H}(3 \mathrm{AA})$ & 0.8799 & $\mathrm{C}(19)-\mathrm{H}(19 \mathrm{C})$ & $0.916(13)$ \\
\hline $\mathrm{O}(3)-\mathrm{H}(3 \mathrm{BA})$ & 0.8997 & & \\
\hline $\mathrm{O}(3)-\mathrm{H}(3 \mathrm{BB})$ & 0.9629 & $\mathrm{C}(19)-\mathrm{P}(1)-\mathrm{C}(7)$ & $107.73(5)$ \\
\hline $\mathrm{C}(1)-\mathrm{C}(2)$ & $1.5358(16)$ & $\mathrm{C}(19)-\mathrm{P}(1)-\mathrm{C}(13)$ & $109.74(5)$ \\
\hline$C(1)-C(6)$ & $1.5398(14)$ & $\mathrm{C}(7)-\mathrm{P}(1)-\mathrm{C}(13)$ & $112.79(5)$ \\
\hline $\mathrm{C}(1)-\mathrm{H}(1)$ & $0.939(12)$ & $\mathrm{C}(19)-\mathrm{P}(1)-\mathrm{C}(1)$ & $106.55(5)$ \\
\hline$C(2)-C(3)$ & $1.5316(15)$ & $\mathrm{C}(7)-\mathrm{P}(1)-\mathrm{C}(1)$ & $112.06(5)$ \\
\hline $\mathrm{C}(2)-\mathrm{H}(2 \mathrm{~A})$ & $0.974(12)$ & $\mathrm{C}(13)-\mathrm{P}(1)-\mathrm{C}(1)$ & $107.77(5)$ \\
\hline $\mathrm{C}(2)-\mathrm{H}(2 \mathrm{~B})$ & $0.984(13)$ & $\mathrm{H}(1 \mathrm{AA})-\mathrm{O}(1)-\mathrm{H}(1 \mathrm{BA})$ & 117.1 \\
\hline $\mathrm{C}(3)-\mathrm{C}(4)$ & $1.5318(16)$ & $\mathrm{H}(1 \mathrm{AA})-\mathrm{O}(1)-\mathrm{H}(1 \mathrm{BB})$ & 94.4 \\
\hline $\mathrm{C}(3)-\mathrm{H}(3 \mathrm{~A})$ & $0.953(13)$ & $\mathrm{H}(1 \mathrm{BA})-\mathrm{O}(1)-\mathrm{H}(1 \mathrm{BB})$ & 136.7 \\
\hline $\mathrm{C}(3)-\mathrm{H}(3 \mathrm{~B})$ & $0.963(14)$ & $\mathrm{H}(2 \mathrm{AA})-\mathrm{O}(2)-\mathrm{H}(2 \mathrm{BA})$ & 100.0 \\
\hline$C(4)-C(5)$ & $1.5209(17)$ & $\mathrm{H}(3 \mathrm{AA})-\mathrm{O}(3)-\mathrm{H}(3 \mathrm{BA})$ & 118.0 \\
\hline $\mathrm{C}(4)-\mathrm{H}(4 \mathrm{~A})$ & $1.000(14)$ & $\mathrm{H}(3 \mathrm{AA})-\mathrm{O}(3)-\mathrm{H}(3 \mathrm{BB})$ & 95.0 \\
\hline $\mathrm{C}(4)-\mathrm{H}(4 \mathrm{~B})$ & $0.947(13)$ & $\mathrm{H}(3 \mathrm{BA})-\mathrm{O}(3)-\mathrm{H}(3 \mathrm{BB})$ & 129.0 \\
\hline$C(5)-C(6)$ & $1.5320(15)$ & $C(2)-C(1)-C(6)$ & $110.16(9)$ \\
\hline $\mathrm{C}(5)-\mathrm{H}(5 \mathrm{~A})$ & $0.966(13)$ & $\mathrm{C}(2)-\mathrm{C}(1)-\mathrm{P}(1)$ & $116.70(7)$ \\
\hline $\mathrm{C}(5)-\mathrm{H}(5 \mathrm{~B})$ & $0.947(13)$ & $\mathrm{C}(6)-\mathrm{C}(1)-\mathrm{P}(1)$ & $111.88(7)$ \\
\hline $\mathrm{C}(6)-\mathrm{H}(6 \mathrm{~A})$ & $0.926(13)$ & $\mathrm{C}(2)-\mathrm{C}(1)-\mathrm{H}(1)$ & $108.9(8)$ \\
\hline $\mathrm{C}(6)-\mathrm{H}(6 \mathrm{~B})$ & $0.948(12)$ & $\mathrm{C}(6)-\mathrm{C}(1)-\mathrm{H}(1)$ & $107.7(8)$ \\
\hline $\mathrm{C}(7)-\mathrm{C}(8)$ & $1.5323(16)$ & $\mathrm{P}(1)-\mathrm{C}(1)-\mathrm{H}(1)$ & $100.8(7)$ \\
\hline$C(7)-C(12)$ & $1.5485(15)$ & $C(3)-C(2)-C(1)$ & $109.78(9)$ \\
\hline $\mathrm{C}(7)-\mathrm{H}(7)$ & $0.970(13)$ & $\mathrm{C}(3)-\mathrm{C}(2)-\mathrm{H}(2 \mathrm{~A})$ & $108.6(7)$ \\
\hline$C(8)-C(9)$ & $1.5309(16)$ & $\mathrm{C}(1)-\mathrm{C}(2)-\mathrm{H}(2 \mathrm{~A})$ & $110.0(8)$ \\
\hline $\mathrm{C}(8)-\mathrm{H}(8 \mathrm{~A})$ & $0.994(14)$ & $\mathrm{C}(3)-\mathrm{C}(2)-\mathrm{H}(2 \mathrm{~B})$ & $108.5(7)$ \\
\hline $\mathrm{C}(8)-\mathrm{H}(8 \mathrm{~B})$ & $0.954(13)$ & $\mathrm{C}(1)-\mathrm{C}(2)-\mathrm{H}(2 \mathrm{~B})$ & $111.2(8)$ \\
\hline $\mathrm{C}(9)-\mathrm{C}(10)$ & $1.5303(17)$ & $\mathrm{H}(2 \mathrm{~A})-\mathrm{C}(2)-\mathrm{H}(2 \mathrm{~B})$ & $108.7(10)$ \\
\hline $\mathrm{C}(9)-\mathrm{H}(9 \mathrm{~A})$ & $0.967(13)$ & $C(2)-C(3)-C(4)$ & $111.38(10)$ \\
\hline $\mathrm{C}(9)-\mathrm{H}(9 \mathrm{~B})$ & $0.959(14)$ & $\mathrm{C}(2)-\mathrm{C}(3)-\mathrm{H}(3 \mathrm{~A})$ & $108.0(8)$ \\
\hline$C(10)-C(11)$ & $1.5193(17)$ & $\mathrm{C}(4)-\mathrm{C}(3)-\mathrm{H}(3 \mathrm{~A})$ & $108.7(8)$ \\
\hline $\mathrm{C}(10)-\mathrm{H}(10 \mathrm{~A})$ & $0.975(14)$ & $\mathrm{C}(2)-\mathrm{C}(3)-\mathrm{H}(3 \mathrm{~B})$ & $109.8(7)$ \\
\hline $\mathrm{C}(10)-\mathrm{H}(10 \mathrm{~B})$ & $0.986(14)$ & $\mathrm{C}(4)-\mathrm{C}(3)-\mathrm{H}(3 \mathrm{~B})$ & $109.2(7)$ \\
\hline $\mathrm{C}(11)-\mathrm{C}(12)$ & $1.5288(15)$ & $\mathrm{H}(3 \mathrm{~A})-\mathrm{C}(3)-\mathrm{H}(3 \mathrm{~B})$ & $109.8(11)$ \\
\hline $\mathrm{C}(11)-\mathrm{H}(11 \mathrm{~A})$ & $0.974(13)$ & $C(5)-C(4)-C(3)$ & $111.53(10)$ \\
\hline $\mathrm{C}(11)-\mathrm{H}(11 \mathrm{~B})$ & $0.961(13)$ & $\mathrm{C}(5)-\mathrm{C}(4)-\mathrm{H}(4 \mathrm{~A})$ & $109.3(8)$ \\
\hline $\mathrm{C}(12)-\mathrm{H}(12 \mathrm{~A})$ & $0.927(14)$ & $\mathrm{C}(3)-\mathrm{C}(4)-\mathrm{H}(4 \mathrm{~A})$ & 109.2(8) \\
\hline $\mathrm{C}(12)-\mathrm{H}(12 \mathrm{~B})$ & $0.983(12)$ & $\mathrm{C}(5)-\mathrm{C}(4)-\mathrm{H}(4 \mathrm{~B})$ & $108.7(8)$ \\
\hline$C(13)-C(14)$ & $1.5373(14)$ & $\mathrm{C}(3)-\mathrm{C}(4)-\mathrm{H}(4 \mathrm{~B})$ & $109.3(8)$ \\
\hline $\mathrm{C}(13)-\mathrm{C}(18)$ & $1.5449(15)$ & $\mathrm{H}(4 \mathrm{~A})-\mathrm{C}(4)-\mathrm{H}(4 \mathrm{~B})$ & $108.8(11)$ \\
\hline $\mathrm{C}(13)-\mathrm{H}(13)$ & $0.931(13)$ & $C(4)-C(5)-C(6)$ & $111.05(9)$ \\
\hline $\mathrm{C}(14)-\mathrm{C}(15)$ & $1.5339(15)$ & $\mathrm{C}(4)-\mathrm{C}(5)-\mathrm{H}(5 \mathrm{~A})$ & 109.7(8) \\
\hline $\mathrm{C}(14)-\mathrm{H}(14 \mathrm{~A})$ & $1.029(13)$ & $\mathrm{C}(6)-\mathrm{C}(5)-\mathrm{H}(5 \mathrm{~A})$ & $109.2(7)$ \\
\hline $\mathrm{C}(14)-\mathrm{H}(14 \mathrm{~B})$ & $0.919(14)$ & $\mathrm{C}(4)-\mathrm{C}(5)-\mathrm{H}(5 \mathrm{~B})$ & $113.0(8)$ \\
\hline$C(15)-C(16)$ & $1.5246(16)$ & $\mathrm{C}(6)-\mathrm{C}(5)-\mathrm{H}(5 \mathrm{~B})$ & $108.0(7)$ \\
\hline $\mathrm{C}(15)-\mathrm{H}(15 \mathrm{~A})$ & $0.967(13)$ & $\mathrm{H}(5 \mathrm{~A})-\mathrm{C}(5)-\mathrm{H}(5 \mathrm{~B})$ & $105.8(11)$ \\
\hline $\mathrm{C}(15)-\mathrm{H}(15 \mathrm{~B})$ & $0.970(14)$ & $C(5)-C(6)-C(1)$ & $110.04(9)$ \\
\hline$C(16)-C(17)$ & $1.5227(17)$ & $\mathrm{C}(5)-\mathrm{C}(6)-\mathrm{H}(6 \mathrm{~A})$ & $110.8(7)$ \\
\hline
\end{tabular}




\begin{tabular}{|c|c|}
\hline$C(1)-C(6)-H(6 A)$ & $110.6(7)$ \\
\hline $\mathrm{C}(5)-\mathrm{C}(6)-\mathrm{H}(6 \mathrm{~B})$ & $110.1(7)$ \\
\hline $\mathrm{C}(1)-\mathrm{C}(6)-\mathrm{H}(6 \mathrm{~B})$ & $109.1(7)$ \\
\hline $\mathrm{H}(6 \mathrm{~A})-\mathrm{C}(6)-\mathrm{H}(6 \mathrm{~B})$ & $106.1(10)$ \\
\hline $\mathrm{C}(8)-\mathrm{C}(7)-\mathrm{C}(12)$ & $112.57(9)$ \\
\hline $\mathrm{C}(8)-\mathrm{C}(7)-\mathrm{P}(1)$ & $112.98(7)$ \\
\hline $\mathrm{C}(12)-\mathrm{C}(7)-\mathrm{P}(1)$ & $111.83(7)$ \\
\hline $\mathrm{C}(8)-\mathrm{C}(7)-\mathrm{H}(7)$ & $110.8(8)$ \\
\hline $\mathrm{C}(12)-\mathrm{C}(7)-\mathrm{H}(7)$ & $106.9(8)$ \\
\hline $\mathrm{P}(1)-\mathrm{C}(7)-\mathrm{H}(7)$ & $101.0(8)$ \\
\hline $\mathrm{C}(9)-\mathrm{C}(8)-\mathrm{C}(7)$ & $111.29(10)$ \\
\hline $\mathrm{C}(9)-\mathrm{C}(8)-\mathrm{H}(8 \mathrm{~A})$ & $107.3(8)$ \\
\hline $\mathrm{C}(7)-\mathrm{C}(8)-\mathrm{H}(8 \mathrm{~A})$ & $111.6(8)$ \\
\hline $\mathrm{C}(9)-\mathrm{C}(8)-\mathrm{H}(8 \mathrm{~B})$ & $110.5(8)$ \\
\hline $\mathrm{C}(7)-\mathrm{C}(8)-\mathrm{H}(8 \mathrm{~B})$ & $110.5(8)$ \\
\hline $\mathrm{H}(8 \mathrm{~A})-\mathrm{C}(8)-\mathrm{H}(8 \mathrm{~B})$ & $105.6(11)$ \\
\hline $\mathrm{C}(10)-\mathrm{C}(9)-\mathrm{C}(8)$ & $111.01(10)$ \\
\hline $\mathrm{C}(10)-\mathrm{C}(9)-\mathrm{H}(9 \mathrm{~A})$ & $109.0(8)$ \\
\hline $\mathrm{C}(8)-\mathrm{C}(9)-\mathrm{H}(9 \mathrm{~A})$ & $110.1(8)$ \\
\hline $\mathrm{C}(10)-\mathrm{C}(9)-\mathrm{H}(9 \mathrm{~B})$ & $112.4(8)$ \\
\hline $\mathrm{C}(8)-\mathrm{C}(9)-\mathrm{H}(9 \mathrm{~B})$ & 109.1(8) \\
\hline H(9A)-C(9)-H(9B) & $105.1(11)$ \\
\hline $\mathrm{C}(11)-\mathrm{C}(10)-\mathrm{C}(9)$ & $110.89(10)$ \\
\hline $\mathrm{C}(11)-\mathrm{C}(10)-\mathrm{H}(10 \mathrm{~A})$ & $110.9(8)$ \\
\hline $\mathrm{C}(9)-\mathrm{C}(10)-\mathrm{H}(10 \mathrm{~A})$ & $109.1(8)$ \\
\hline $\mathrm{C}(11)-\mathrm{C}(10)-\mathrm{H}(10 \mathrm{~B})$ & $108.9(8)$ \\
\hline $\mathrm{C}(9)-\mathrm{C}(10)-\mathrm{H}(10 \mathrm{~B})$ & 111.1(8) \\
\hline $\mathrm{H}(10 \mathrm{~A})-\mathrm{C}(10)-\mathrm{H}(10 \mathrm{~B})$ & $105.8(11)$ \\
\hline $\mathrm{C}(10)-\mathrm{C}(11)-\mathrm{C}(12)$ & $111.72(9)$ \\
\hline $\mathrm{C}(10)-\mathrm{C}(11)-\mathrm{H}(11 \mathrm{~A})$ & $109.5(8)$ \\
\hline $\mathrm{C}(12)-\mathrm{C}(11)-\mathrm{H}(11 \mathrm{~A})$ & $107.5(7)$ \\
\hline $\mathrm{C}(10)-\mathrm{C}(11)-\mathrm{H}(11 \mathrm{~B})$ & $113.6(8)$ \\
\hline $\mathrm{C}(12)-\mathrm{C}(11)-\mathrm{H}(11 \mathrm{~B})$ & $106.8(7)$ \\
\hline $\mathrm{H}(11 \mathrm{~A})-\mathrm{C}(11)-\mathrm{H}(11 \mathrm{~B})$ & $107.4(11)$ \\
\hline $\mathrm{C}(11)-\mathrm{C}(12)-\mathrm{C}(7)$ & 111.27(9) \\
\hline $\mathrm{C}(11)-\mathrm{C}(12)-\mathrm{H}(12 \mathrm{~A})$ & $108.4(8)$ \\
\hline $\mathrm{C}(7)-\mathrm{C}(12)-\mathrm{H}(12 \mathrm{~A})$ & $109.2(8)$ \\
\hline $\mathrm{C}(11)-\mathrm{C}(12)-\mathrm{H}(12 \mathrm{~B})$ & $109.4(7)$ \\
\hline $\mathrm{C}(7)-\mathrm{C}(12)-\mathrm{H}(12 \mathrm{~B})$ & $110.7(7)$ \\
\hline $\mathrm{H}(12 \mathrm{~A})-\mathrm{C}(12)-\mathrm{H}(12 \mathrm{~B})$ & $107.8(11)$ \\
\hline $\mathrm{C}(14)-\mathrm{C}(13)-\mathrm{C}(18)$ & $110.40(9)$ \\
\hline $\mathrm{C}(14)-\mathrm{C}(13)-\mathrm{P}(1)$ & $114.13(7)$ \\
\hline $\mathrm{C}(18)-\mathrm{C}(13)-\mathrm{P}(1)$ & $109.12(7)$ \\
\hline $\mathrm{C}(14)-\mathrm{C}(13)-\mathrm{H}(13)$ & $107.9(7)$ \\
\hline $\mathrm{C}(18)-\mathrm{C}(13)-\mathrm{H}(13)$ & $108.6(7)$ \\
\hline $\mathrm{P}(1)-\mathrm{C}(13)-\mathrm{H}(13)$ & $106.5(7)$ \\
\hline $\mathrm{C}(15)-\mathrm{C}(14)-\mathrm{C}(13)$ & $111.06(9)$ \\
\hline $\mathrm{C}(15)-\mathrm{C}(14)-\mathrm{H}(14 \mathrm{~A})$ & $108.1(7)$ \\
\hline $\mathrm{C}(13)-\mathrm{C}(14)-\mathrm{H}(14 \mathrm{~A})$ & $110.1(7)$ \\
\hline $\mathrm{C}(15)-\mathrm{C}(14)-\mathrm{H}(14 \mathrm{~B})$ & $108.2(8)$ \\
\hline $\mathrm{C}(13)-\mathrm{C}(14)-\mathrm{H}(14 \mathrm{~B})$ & $110.4(8)$ \\
\hline $\mathrm{H}(14 \mathrm{~A})-\mathrm{C}(14)-\mathrm{H}(14 \mathrm{~B})$ & $109.0(10)$ \\
\hline $\mathrm{C}(16)-\mathrm{C}(15)-\mathrm{C}(14)$ & $111.79(9)$ \\
\hline $\mathrm{C}(16)-\mathrm{C}(15)-\mathrm{H}(15 \mathrm{~A})$ & $110.5(7)$ \\
\hline $\mathrm{C}(14)-\mathrm{C}(15)-\mathrm{H}(15 \mathrm{~A})$ & $109.2(7)$ \\
\hline $\mathrm{C}(16)-\mathrm{C}(15)-\mathrm{H}(15 \mathrm{~B})$ & $109.3(7)$ \\
\hline $\mathrm{C}(14)-\mathrm{C}(15)-\mathrm{H}(15 \mathrm{~B})$ & $111.0(7)$ \\
\hline $\mathrm{H}(15 \mathrm{~A})-\mathrm{C}(15)-\mathrm{H}(15 \mathrm{~B})$ & $104.8(10)$ \\
\hline $\mathrm{C}(17)-\mathrm{C}(16)-\mathrm{C}(15)$ & $110.84(9)$ \\
\hline
\end{tabular}

$\begin{array}{ll}\mathrm{C}(17)-\mathrm{C}(16)-\mathrm{H}(16 \mathrm{~A}) & 109.7(7) \\ \mathrm{C}(15)-\mathrm{C}(16)-\mathrm{H}(16 \mathrm{~A}) & 108.9(7) \\ \mathrm{C}(17)-\mathrm{C}(16)-\mathrm{H}(16 \mathrm{~B}) & 111.0(8) \\ \mathrm{C}(15)-\mathrm{C}(16)-\mathrm{H}(16 \mathrm{~B}) & 110.9(8) \\ \mathrm{H}(16 \mathrm{~A})-\mathrm{C}(16)-\mathrm{H}(16 \mathrm{~B}) & 105.3(11) \\ \mathrm{C}(16)-\mathrm{C}(17)-\mathrm{C}(18) & 111.11(10) \\ \mathrm{C}(16)-\mathrm{C}(17)-\mathrm{H}(17 \mathrm{~A}) & 108.9(7) \\ \mathrm{C}(18)-\mathrm{C}(17)-\mathrm{H}(17 \mathrm{~A}) & 110.6(7) \\ \mathrm{C}(16)-\mathrm{C}(17)-\mathrm{H}(17 \mathrm{~B}) & 109.9(9) \\ \mathrm{C}(18)-\mathrm{C}(17)-\mathrm{H}(17 \mathrm{~B}) & 108.8(9) \\ \mathrm{H}(17 \mathrm{~A})-\mathrm{C}(17)-\mathrm{H}(17 \mathrm{~B}) & 107.4(12) \\ \mathrm{C}(17)-\mathrm{C}(18)-\mathrm{C}(13) & 111.06(9) \\ \mathrm{C}(17)-\mathrm{C}(18)-\mathrm{H}(18 \mathrm{~A}) & 108.4(8) \\ \mathrm{C}(13)-\mathrm{C}(18)-\mathrm{H}(18 \mathrm{~A}) & 106.3(8) \\ \mathrm{C}(17)-\mathrm{C}(18)-\mathrm{H}(18 \mathrm{~B}) & 111.1(8) \\ \mathrm{C}(13)-\mathrm{C}(18)-\mathrm{H}(18 \mathrm{~B}) & 111.3(7) \\ \mathrm{H}(18 \mathrm{~A})-\mathrm{C}(18)-\mathrm{H}(18 \mathrm{~B}) & 108.4(11) \\ \mathrm{P}(1)-\mathrm{C}(19)-\mathrm{H}(19 \mathrm{~A}) & 108.8(8) \\ \mathrm{P}(1)-\mathrm{C}(19)-\mathrm{H}(19 \mathrm{~B}) & 109.2(8) \\ \mathrm{H}(19 \mathrm{~A})-\mathrm{C}(19)-\mathrm{H}(19 \mathrm{~B}) & 108.8(11) \\ \mathrm{P}(1)-\mathrm{C}(19)-\mathrm{H}(19 \mathrm{C}) & 109.6(8) \\ \mathrm{H}(19 \mathrm{~A})-\mathrm{C}(19)-\mathrm{H}(19 \mathrm{C}) & 110.1(11) \\ \mathrm{H}(19 \mathrm{~B})-\mathrm{C}(19)-\mathrm{H}(19 \mathrm{C}) & 110.3(11) \\ & \end{array}$


Table S.4. Anisotropic displacement parameters $\left(\AA^{2} \times 10^{4}\right)$ for 7 (CCDC 288113). The anisotropic displacement factor exponent takes the form: $-2 \pi^{2}\left[h^{2} a^{* 2} U^{11}+\ldots+2 h k a^{*} b^{*} U^{12}\right]$

\begin{tabular}{lrrrrrr}
\hline & $\mathrm{U}^{11}$ & $\mathrm{U}^{22}$ & $\mathrm{U}^{33}$ & $\mathrm{U}^{23}$ & $\mathrm{U}^{13}$ & $\mathrm{U}^{12}$ \\
\hline $\mathrm{Cl}(1)$ & $205(1)$ & $166(1)$ & $314(2)$ & $-3(1)$ & $-21(1)$ & $-98(1)$ \\
$\mathrm{P}(1)$ & $113(1)$ & $96(1)$ & $116(1)$ & $4(1)$ & $-27(1)$ & $-39(1)$ \\
$\mathrm{C}(1)$ & $129(4)$ & $98(5)$ & $136(6)$ & $4(4)$ & $-38(4)$ & $-40(4)$ \\
$\mathrm{C}(2)$ & $156(5)$ & $149(5)$ & $150(6)$ & $36(4)$ & $-25(4)$ & $-43(4)$ \\
$\mathrm{C}(3)$ & $164(5)$ & $165(5)$ & $194(7)$ & $64(4)$ & $-37(5)$ & $-41(4)$ \\
$\mathrm{C}(4)$ & $147(5)$ & $182(6)$ & $237(7)$ & $50(5)$ & $-46(5)$ & $-23(4)$ \\
$\mathrm{C}(5)$ & $121(4)$ & $167(5)$ & $199(7)$ & $10(4)$ & $-15(4)$ & $-25(4)$ \\
$\mathrm{C}(6)$ & $134(4)$ & $140(5)$ & $146(6)$ & $15(4)$ & $-21(4)$ & $-53(4)$ \\
$\mathrm{C}(7)$ & $129(4)$ & $106(5)$ & $143(6)$ & $5(4)$ & $-28(4)$ & $-50(4)$ \\
$\mathrm{C}(8)$ & $232(5)$ & $143(5)$ & $143(6)$ & $18(4)$ & $-72(5)$ & $-78(4)$ \\
$\mathrm{C}(9)$ & $322(6)$ & $170(6)$ & $207(7)$ & $7(4)$ & $-130(5)$ & $-106(5)$ \\
$\mathrm{C}(10)$ & $293(6)$ & $126(5)$ & $221(7)$ & $-14(4)$ & $-85(5)$ & $-71(5)$ \\
$\mathrm{C}(11)$ & $204(5)$ & $129(5)$ & $206(6)$ & $26(4)$ & $-47(5)$ & $-82(4)$ \\
$\mathrm{C}(12)$ & $187(5)$ & $136(5)$ & $126(6)$ & $26(4)$ & $-48(4)$ & $-71(4)$ \\
$\mathrm{C}(13)$ & $127(4)$ & $112(5)$ & $135(6)$ & $2(4)$ & $-27(4)$ & $-52(4)$ \\
$\mathrm{C}(14)$ & $122(4)$ & $128(5)$ & $180(6)$ & $0(4)$ & $-27(4)$ & $-40(4)$ \\
$\mathrm{C}(15)$ & $133(4)$ & $175(5)$ & $207(7)$ & $-29(4)$ & $-6(4)$ & $-57(4)$ \\
$\mathrm{C}(16)$ & $153(5)$ & $244(6)$ & $243(7)$ & $-24(5)$ & $-29(5)$ & $-112(4)$ \\
$\mathrm{C}(17)$ & $202(5)$ & $179(6)$ & $290(8)$ & $-34(5)$ & $-19(5)$ & $-118(5)$ \\
$\mathrm{C}(18)$ & $165(5)$ & $147(5)$ & $249(7)$ & $-45(4)$ & $-18(5)$ & $-75(4)$ \\
$\mathrm{C}(19)$ & $164(5)$ & $135(5)$ & $134(6)$ & $1(4)$ & $-38(4)$ & $-58(4)$ \\
$\mathrm{O}(1)$ & $188(4)$ & $217(4)$ & $380(6)$ & $48(4)$ & $-88(4)$ & $-91(3)$ \\
$\mathrm{O}(2)$ & $229(4)$ & $230(4)$ & $388(6)$ & $-45(4)$ & $-84(4)$ & $-86(4)$ \\
$\mathrm{O}(3)$ & $214(4)$ & $255(5)$ & $403(6)$ & $-48(4)$ & $-102(4)$ & $-60(4)$ \\
& & & & & & \\
\hline
\end{tabular}


Table S.5. Hydrogen coordinates $\left(\times 10^{4}\right)$ and isotropic displacement parameters $\left(\AA^{2} \times 10^{3}\right)$ for 7 (CCDC 288113).

\begin{tabular}{|c|c|c|c|c|}
\hline & $\mathrm{x}$ & $y$ & $\mathrm{z}$ & $\mathrm{U}_{\text {iso }}$ \\
\hline $\mathrm{H}(1 \mathrm{AA})$ & 3337 & 9429 & 5636 & 31 \\
\hline $\mathrm{H}(1 \mathrm{BA})$ & 4742 & 9629 & 5146 & 31 \\
\hline $\mathrm{H}(1 \mathrm{BB})$ & 4396 & 8244 & 5142 & 31 \\
\hline $\mathrm{H}(2 \mathrm{AA})$ & 1078 & 9245 & 6014 & 34 \\
\hline $\mathrm{H}(2 \mathrm{BA})$ & 592 & 10666 & 5920 & 34 \\
\hline $\mathrm{H}(3 \mathrm{AA})$ & 6537 & 3222 & 5299 & 36 \\
\hline $\mathrm{H}(3 \mathrm{BA})$ & 4983 & 4502 & 5208 & 36 \\
\hline $\mathrm{H}(3 \mathrm{BB})$ & 5590 & 2644 & 5145 & 36 \\
\hline $\mathrm{H}(1)$ & 9011(14) & $3950(13)$ & 7011(10) & $18(3)$ \\
\hline $\mathrm{H}(2 \mathrm{~A})$ & $9006(14)$ & $4616(13)$ & $9118(10)$ & $17(3)$ \\
\hline $\mathrm{H}(2 \mathrm{~B})$ & 7892(15) & 3963(13) & $8913(10)$ & $20(3)$ \\
\hline $\mathrm{H}(3 \mathrm{~A})$ & $10077(15)$ & 1774(14) & $8158(11)$ & $21(3)$ \\
\hline $\mathrm{H}(3 \mathrm{~B})$ & 10131(14) & 2034(13) & $9336(11)$ & $19(3)$ \\
\hline $\mathrm{H}(4 \mathrm{~A})$ & $12021(15)$ & 2916(14) & $8645(12)$ & $24(3)$ \\
\hline $\mathrm{H}(4 \mathrm{~B})$ & $12606(15)$ & $1330(15)$ & $8087(11)$ & $25(3)$ \\
\hline $\mathrm{H}(5 \mathrm{~A})$ & $11936(15)$ & $2360(14)$ & $6510(11)$ & $21(3)$ \\
\hline $\mathrm{H}(5 \mathrm{~B})$ & $12971(15)$ & 3011(13) & $6731(10)$ & $19(3)$ \\
\hline $\mathrm{H}(6 \mathrm{~A})$ & 10795(13) & $4962(13)$ & $6355(11)$ & $12(3)$ \\
\hline $\mathrm{H}(6 \mathrm{~B})$ & 10789(13) & $5215(13)$ & $7495(10)$ & $15(3)$ \\
\hline $\mathrm{H}(7)$ & $8862(15)$ & 7638(14) & 7299(11) & $24(3)$ \\
\hline $\mathrm{H}(8 \mathrm{~A})$ & 6313(16) & $8405(15)$ & $9255(12)$ & $30(4)$ \\
\hline $\mathrm{H}(8 \mathrm{~B})$ & $8052(15)$ & 7317(15) & $9184(11)$ & $24(3)$ \\
\hline $\mathrm{H}(9 \mathrm{~A})$ & $8744(16)$ & $9320(14)$ & $8876(11)$ & $23(3)$ \\
\hline $\mathrm{H}(9 \mathrm{~B})$ & $7420(14)$ & $9654(14)$ & $9918(12)$ & $21(3)$ \\
\hline $\mathrm{H}(10 \mathrm{~A})$ & $5560(16)$ & $11220(15)$ & $8956(11)$ & $28(4)$ \\
\hline $\mathrm{H}(10 \mathrm{~B})$ & 6833(15) & $11800(15)$ & $8790(11)$ & $26(4)$ \\
\hline $\mathrm{H}(11 \mathrm{~A})$ & $8167(15)$ & 10492(14) & 7089(11) & $23(3)$ \\
\hline $\mathrm{H}(11 \mathrm{~B})$ & $6456(14)$ & 11564(14) & 7049(11) & $19(3)$ \\
\hline $\mathrm{H}(12 \mathrm{~A})$ & $7208(14)$ & $9232(14)$ & $6345(11)$ & $20(3)$ \\
\hline $\mathrm{H}(12 \mathrm{~B})$ & $5722(14)$ & $9651(13)$ & 7297(10) & $16(3)$ \\
\hline $\mathrm{H}(13)$ & $5719(14)$ & 6211(13) & $8789(11)$ & $14(3)$ \\
\hline $\mathrm{H}(14 \mathrm{~A})$ & $4284(14)$ & 8721(14) & $8438(11)$ & $20(3)$ \\
\hline $\mathrm{H}(14 \mathrm{~B})$ & $4127(14)$ & 8131(14) & 7382(11) & $18(3)$ \\
\hline $\mathrm{H}(15 \mathrm{~A})$ & 1803(15) & $8737(14)$ & 8693(11) & $21(3)$ \\
\hline $\mathrm{H}(15 \mathrm{~B})$ & 2651(14) & 7683(13) & 9494(11) & $16(3)$ \\
\hline $\mathrm{H}(16 \mathrm{~A})$ & $2410(15)$ & 6711(14) & 7553(12) & $21(3)$ \\
\hline $\mathrm{H}(16 \mathrm{~B})$ & 1587(16) & $6467(15)$ & 8711(12) & $30(4)$ \\
\hline $\mathrm{H}(17 \mathrm{~A})$ & 3992(14) & $4795(13)$ & $9070(11)$ & $19(3)$ \\
\hline $\mathrm{H}(17 \mathrm{~B})$ & $3859(16)$ & $4267(16)$ & $8009(12)$ & $37(4)$ \\
\hline $\mathrm{H}(18 \mathrm{~A})$ & $5385(14)$ & $5321(14)$ & $6927(11)$ & 19(3) \\
\hline $\mathrm{H}(18 \mathrm{~B})$ & $6364(15)$ & $4153(14)$ & $7630(11)$ & $21(3)$ \\
\hline $\mathrm{H}(19 \mathrm{~A})$ & $8459(15)$ & $6619(14)$ & $5481(11)$ & $24(3)$ \\
\hline $\mathrm{H}(19 \mathrm{~B})$ & $6622(16)$ & $7263(15)$ & $5758(11)$ & $26(4)$ \\
\hline $\mathrm{H}(19 \mathrm{C})$ & $7691(15)$ & $5551(14)$ & $5631(11)$ & $21(3)$ \\
\hline
\end{tabular}


Table S.6. Hydrogen bonds for 7 (CCDC 288113) [ $\left[\AA\right.$ and $^{\circ}$ ].

\begin{tabular}{lcccc}
\hline D-H...A & $\mathrm{d}(\mathrm{D}-\mathrm{H})$ & $\mathrm{d}(\mathrm{H} . . . \mathrm{A})$ & $\mathrm{d}(\mathrm{D} \ldots \mathrm{A})$ & $<(\mathrm{DHA})$ \\
\hline $\mathrm{O}(1)-\mathrm{H}(1 \mathrm{AA}) \ldots \mathrm{O}(2)$ & 0.86 & 1.92 & $2.7656(11)$ & 168.1 \\
$\mathrm{O}(1)-\mathrm{H}(1 \mathrm{BA}) \ldots \mathrm{O}(1) \# 1$ & 0.84 & 1.91 & $2.7553(16)$ & 179.8 \\
$\mathrm{O}(1)-\mathrm{H}(1 \mathrm{BB}) \ldots \mathrm{O}(3) \# 2$ & 0.84 & 1.94 & $2.7856(12)$ & 178.6 \\
& & & & \\
$\mathrm{O}(2)-\mathrm{H}(2 \mathrm{AA}) \ldots \mathrm{Cl}(1)$ & 0.78 & 2.45 & $3.2242(9)$ & 171.1 \\
$\mathrm{O}(2)-\mathrm{H}(2 \mathrm{BA}) \ldots \mathrm{Cl}(1) \# 3$ & 0.90 & 2.25 & $3.1494(10)$ & 177.4 \\
& & & & \\
$\mathrm{O}(3)-\mathrm{H}(3 \mathrm{AA}) \ldots \mathrm{Cl}(1) \# 2$ & 0.88 & 2.30 & $3.1747(9)$ & 174.6 \\
$\mathrm{O}(3)-\mathrm{H}(3 \mathrm{BA}) \ldots \mathrm{O}(3) \# 2$ & 0.90 & 1.92 & $2.7914(18)$ & 162.3 \\
$\mathrm{O}(3)-\mathrm{H}(3 \mathrm{BB}) \ldots \mathrm{O}(1) \# 2$ & 0.96 & 1.82 & $2.7856(12)$ & 177.1
\end{tabular}

Other Hydrogen Donor-Acceptor Interactions

$\begin{array}{lllll}\mathrm{C}(19)-\mathrm{H}(19 \mathrm{~A}) \ldots \mathrm{Cl}(1) \# 4 & 0.959(14) & 2.726(14) & 3.6522(12) & 162.5(11) \\ \mathrm{C}(19)-\mathrm{H}(19 \mathrm{~B}) \ldots \mathrm{O}(1) & 0.978(13) & 2.317(14) & 3.2919(14) & 174.0(11) \\ \mathrm{C}(19)-\mathrm{H}(19 \mathrm{C}) \ldots \mathrm{Cl}(1) \# 2 & 0.916(13) & 2.749(13) & 3.6128(12) & 157.6(10)\end{array}$

Symmetry transformations used to generate equivalent atoms:

$\# 1-x+1,-y+2,-z+1$

$\# 2-x+1,-y+1,-z+1$

$\# 3-x,-y+2,-z+1$

$\# 4 \mathrm{x}+1, \mathrm{y}, \mathrm{z}$ 


\section{Crystal Structure Analysis of 21}

\section{Contents}

Table S.8. Crystal data

Figure Minimum overlap

Table S.9. Atomic Coordinates

Table S.10. Selected bond distances and angles

Table S.11. Full bond distances and angles

Table S.12. Anisotropic displacement parameters

Table S.13. Hydrogen atomic coordinates

Table S.14. Observed and calculated structure factors (available upon request)

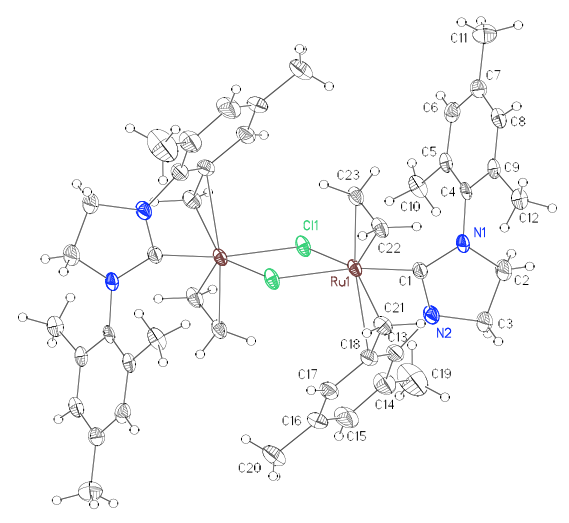

Note: Crystallographic data have been deposited at the CCDC, 12 Union Road, Cambridge CB2 1EZ, UK and copies can be obtained on request, free of charge, by quoting the publication citation and the deposition number 612720 . 
Table S.8. Crystal data and structure refinement for 21 (CCDC 612720).

Empirical formula

Formula weight

Crystallization Solvent

Crystal Habit

Crystal size

Crystal color

Type of diffractometer

Wavelength

Data Collection Temperature

$\theta$ range for 8556 reflections used in lattice determination

Unit cell dimensions

Volume

$\mathrm{Z}$

Crystal system

Space group

Density (calculated)

$\mathrm{F}(000)$

Data collection program

$\theta$ range for data collection

Completeness to $\theta=34.93^{\circ}$

Index ranges

Data collection scan type

Data reduction program

Reflections collected

Independent reflections

Absorption coefficient

Absorption correction

Max. and min. transmission
$\mathrm{C}_{46} \mathrm{H}_{58} \mathrm{~N}_{4} \mathrm{Cl}_{2} \mathrm{Ru}_{2}$

940.00

Toluene/pentane

Plate

$0.21 \times 0.18 \times 0.07 \mathrm{~mm}^{3}$

Dichroic - Red/brown

\section{Data Collection}

Bruker SMART 1000

$0.71073 \AA ̊ \mathrm{MoK} \alpha$

100(2) K

2.21 to $33.51^{\circ}$

$a=9.8735(6) \AA$

$\mathrm{b}=10.7053(7) \AA$

$\alpha=100.828(2)^{\circ}$

$\beta=98.018(2)^{\circ}$

$\mathrm{c}=11.8315(7) \AA$

$\gamma=116.4470(10)^{\circ}$

1063.77(11) $\AA^{3}$

1

Triclinic

P-1

$1.467 \mathrm{Mg} / \mathrm{m}^{3}$

484

Bruker SMART v5.630

1.81 to $34.93^{\circ}$

$84.1 \%$

$-15 \leq \mathrm{h} \leq 15,-13 \leq \mathrm{k} \leq 16,-18 \leq 1 \leq 18$

$\omega$ scans at $6 \phi$ settings

Bruker SAINT v6.45A

19483

$7835\left[\mathrm{R}_{\mathrm{int}}=0.0644\right]$

$0.872 \mathrm{~mm}^{-1}$

None

0.9415 and 0.8380 
Table S.8. (cont.)

\section{Structure solution and Refinement}

Structure solution program

Primary solution method

Secondary solution method

Hydrogen placement

Structure refinement program

Refinement method

Data / restraints / parameters

Treatment of hydrogen atoms

Goodness-of-fit on $\mathrm{F}^{2}$

Final $R$ indices [I $>2 \sigma(\mathrm{I}), 5514$ reflections]

$\mathrm{R}$ indices (all data)

Type of weighting scheme used

Weighting scheme used

Max shift/error

Average shift/error

Largest diff. peak and hole
Bruker XS v6.12

Direct methods

Difference Fourier map

Difference Fourier map

Bruker XL v6.12

Full matrix least-squares on $\mathrm{F}^{2}$

7835 / 0 / 360

Unrestrained

1.146

$\mathrm{R} 1=0.0422, w \mathrm{R} 2=0.0667$

$\mathrm{R} 1=0.0724, w \mathrm{R} 2=0.0714$

Sigma

$w=1 / \sigma^{2}\left(\mathrm{Fo}^{2}\right)$

0.001

0.000

1.257 and -1.008 e. $\AA^{-3}$

\section{Special Refinement Details}

Refinement of $\mathrm{F}^{2}$ against ALL reflections. The weighted R-factor $(w \mathrm{R})$ and goodness of fit $(\mathrm{S})$ are based on $\mathrm{F}^{2}$, conventional R-factors $(R)$ are based on $F$, with $F$ set to zero for negative $F^{2}$. The threshold expression of $F^{2}>2 \sigma\left(F^{2}\right)$ is used only for calculating R-factors $(\mathrm{gt})$ etc. and is not relevant to the choice of reflections for refinement. R-factors based on $\mathrm{F}^{2}$ are statistically about twice as large as those based on F, and R-factors based on ALL data will be even larger.

All esds (except the esd in the dihedral angle between two l.s. planes) are estimated using the full covariance matrix. The cell esds are taken into account individually in the estimation of esds in distances, angles and torsion angles; correlations between esds in cell parameters are only used when they are defined by crystal symmetry. An approximate (isotropic) treatment of cell esds is used for estimating esds involving 1.s. planes. 


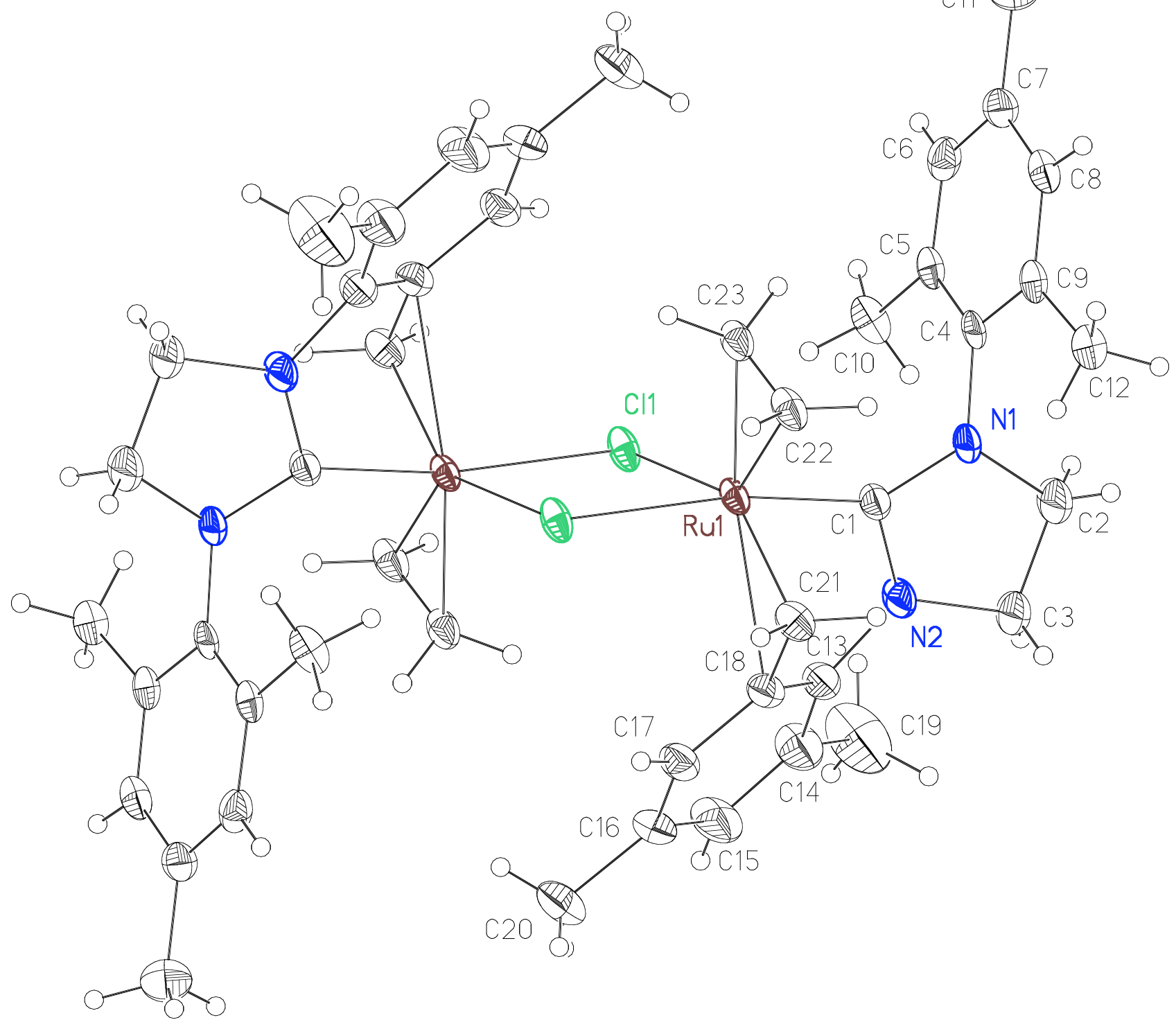


Table S.9. Atomic coordinates $\left(x 1^{4}\right)$ and equivalent isotropic displacement parameters $\left(\AA^{2} x\right.$ $\left.10^{3}\right)$ for 21 (CCDC 612720). $U(\mathrm{eq})$ is defined as the trace of the orthogonalized $U^{i j}$ tensor.

\begin{tabular}{|c|c|c|c|c|}
\hline & $\mathrm{X}$ & $\mathrm{y}$ & $\mathrm{z}$ & $\mathrm{U}_{\mathrm{eq}}$ \\
\hline $\mathrm{Ru}(1)$ & $5580(1)$ & $6883(1)$ & $5879(1)$ & $18(1)$ \\
\hline $\mathrm{Cl}(1)$ & $3635(1)$ & $4368(1)$ & $5729(1)$ & $22(1)$ \\
\hline $\mathrm{N}(1)$ & $5407(2)$ & $8846(2)$ & $8079(2)$ & $23(1)$ \\
\hline $\mathrm{N}(2)$ & $3784(2)$ & $8212(2)$ & $6359(2)$ & $26(1)$ \\
\hline $\mathrm{C}(1)$ & 4919(2) & 7991(2) & $6930(2)$ & $20(1)$ \\
\hline $\mathrm{C}(2)$ & $4490(4)$ & $9596(4)$ & $8297(2)$ & $41(1)$ \\
\hline $\mathrm{C}(3)$ & $3580(4)$ & $9368(3)$ & $7075(2)$ & $32(1)$ \\
\hline $\mathrm{C}(4)$ & $6160(3)$ & $8616(3)$ & $9083(2)$ & $21(1)$ \\
\hline $\mathrm{C}(5)$ & $5372(3)$ & $7352(2)$ & $9424(2)$ & $22(1)$ \\
\hline $\mathrm{C}(6)$ & $6097(3)$ & $7212(3)$ & $10440(2)$ & $26(1)$ \\
\hline $\mathrm{C}(7)$ & $7571(3)$ & $8289(3)$ & $11145(2)$ & $25(1)$ \\
\hline $\mathrm{C}(8)$ & $8293(3)$ & $9536(3)$ & $10795(2)$ & $24(1)$ \\
\hline $\mathrm{C}(9)$ & $7632(3)$ & $9748(3)$ & $9789(2)$ & $22(1)$ \\
\hline$C(10)$ & $3759(3)$ & $6167(3)$ & $8701(2)$ & $31(1)$ \\
\hline $\mathrm{C}(11)$ & $8331(4)$ & $8104(4)$ & $12243(3)$ & $36(1)$ \\
\hline $\mathrm{C}(12)$ & $8429(3)$ & $11170(3)$ & $9504(2)$ & $28(1)$ \\
\hline $\mathrm{C}(13)$ & $3288(3)$ & $7659(3)$ & $5089(2)$ & $26(1)$ \\
\hline$C(14)$ & 1697(3) & $6957(3)$ & $4507(2)$ & $39(1)$ \\
\hline$C(15)$ & $1288(3)$ & $6341(4)$ & $3282(2)$ & $42(1)$ \\
\hline$C(16)$ & $2360(3)$ & $6342(3)$ & $2644(2)$ & $33(1)$ \\
\hline $\mathrm{C}(17)$ & $3906(3)$ & $7047(3)$ & $3241(2)$ & $28(1)$ \\
\hline $\mathrm{C}(18)$ & $4427(3)$ & $7775(3)$ & $4464(2)$ & $24(1)$ \\
\hline C(19) & $482(4)$ & $6844(6)$ & $5159(4)$ & $69(1)$ \\
\hline $\mathrm{C}(20)$ & $1827(4)$ & $5558(4)$ & $1328(2)$ & $45(1)$ \\
\hline $\mathrm{C}(21)$ & $6105(3)$ & $8574(3)$ & $5118(2)$ & $25(1)$ \\
\hline $\mathrm{C}(22)$ & $7925(3)$ & $8196(3)$ & $6807(2)$ & $26(1)$ \\
\hline$C(23)$ & $7314(3)$ & 6891(3) & $7123(2)$ & $26(1)$ \\
\hline
\end{tabular}


Table S.10. Selected bond lengths $[\AA ̊ \AA]$ and angles $\left[{ }^{\circ}\right]$ for 21 (CCDC 612720).

\begin{tabular}{lllc}
\hline $\mathrm{Ru}(1)-\mathrm{C}(1)$ & $1.935(2)$ & $\mathrm{C}(1)-\operatorname{Ru}(1)-\mathrm{C}(21)$ & $82.08(10)$ \\
$\mathrm{Ru}(1)-\mathrm{C}(21)$ & $2.065(3)$ & $\mathrm{C}(1)-\operatorname{Ru}(1)-\mathrm{C}(22)$ & $92.40(9)$ \\
$\mathrm{Ru}(1)-\mathrm{C}(22)$ & $2.086(2)$ & $\mathrm{C}(21)-\operatorname{Ru}(1)-\mathrm{C}(22)$ & $81.43(10)$ \\
$\mathrm{Ru}(1)-\mathrm{C}(23)$ & $2.091(2)$ & $\mathrm{C}(1)-\operatorname{Ru}(1)-\mathrm{C}(23)$ & $99.58(9)$ \\
$\mathrm{Ru}(1)-\mathrm{Cl}(1)$ & $\mathrm{C}(21)-\operatorname{Ru}(1)-\mathrm{C}(23)$ & $120.55(10)$ \\
$\mathrm{Ru}(1)-\mathrm{Cl}(1) \# 1$ & $2.4671(6)$ & $\mathrm{C}(22)-\operatorname{Ru}(1)-\mathrm{C}(23)$ & $39.21(10)$ \\
$\mathrm{Cl}(1)-\mathrm{Ru}(1) \# 1$ & $2.5289(5)$ & $\mathrm{C}(1)-\operatorname{Ru}(1)-\mathrm{Cl}(1)$ & $101.39(7)$ \\
& $2.5290(5)$ & $\mathrm{C}(21)-\operatorname{Ru}(1)-\mathrm{Cl}(1)$ & $144.76(6)$ \\
& & $\mathrm{C}(22)-\operatorname{Ru}(1)-\mathrm{Cl}(1)$ & $132.79(8)$ \\
& & $\mathrm{C}(23)-\operatorname{Ru}(1)-\mathrm{Cl}(1)$ & $93.71(8)$ \\
& & $\mathrm{C}(1)-\operatorname{Ru}(1)-\mathrm{Cl}(1) \# 1$ & $170.94(7)$ \\
& & $\mathrm{C}(21)-\operatorname{Ru}(1)-\mathrm{Cl}(1) \# 1$ & $89.68(7)$ \\
& & $\mathrm{C}(22)-\operatorname{Ru}(1)-\mathrm{Cl}(1) \# 1$ & $90.07(6)$ \\
& & $\mathrm{C}(23)-\operatorname{Ru}(1)-\mathrm{Cl}(1) \# 1$ & $87.82(6)$ \\
& & $\mathrm{Cl}(1)-\operatorname{Ru}(1)-\mathrm{Cl}(1) \# 1$ & $83.190(19)$ \\
& & $\mathrm{Ru}(1)-\mathrm{Cl}(1)-\operatorname{Ru}(1) \# 1$ & $96.809(19)$
\end{tabular}

Symmetry transformations used to generate equivalent atoms:

$\# 1-\mathrm{x}+1,-\mathrm{y}+1,-\mathrm{z}+1$ 
Table S.11. Bond lengths $[\AA]$ and angles $\left[{ }^{\circ}\right]$ for 21 (CCDC 612720).

\begin{tabular}{|c|c|c|c|}
\hline $\mathrm{Ru}(1)-\mathrm{C}(1)$ & $1.935(2)$ & $\mathrm{C}(21)-\mathrm{H}(21 \mathrm{~B})$ & $0.88(3)$ \\
\hline $\mathrm{Ru}(1)-\mathrm{C}(21)$ & $2.065(3)$ & $\mathrm{C}(22)-\mathrm{C}(23)$ & $1.402(4)$ \\
\hline $\mathrm{Ru}(1)-\mathrm{C}(22)$ & $2.086(2)$ & $\mathrm{C}(22)-\mathrm{H}(22 \mathrm{~A})$ & $0.99(2)$ \\
\hline $\mathrm{Ru}(1)-\mathrm{C}(23)$ & $2.091(2)$ & $\mathrm{C}(22)-\mathrm{H}(22 \mathrm{~B})$ & $0.99(3)$ \\
\hline $\mathrm{Ru}(1)-\mathrm{Cl}(1)$ & $2.4671(6)$ & $\mathrm{C}(23)-\mathrm{H}(23 \mathrm{~A})$ & $1.00(3)$ \\
\hline $\mathrm{Ru}(1)-\mathrm{Cl}(1) \# 1$ & $2.5289(5)$ & $\mathrm{C}(23)-\mathrm{H}(23 \mathrm{~B})$ & $0.94(2)$ \\
\hline $\mathrm{Cl}(1)-\mathrm{Ru}(1) \# 1$ & $2.5290(5)$ & & \\
\hline $\mathrm{N}(1)-\mathrm{C}(1)$ & $1.369(2)$ & $\mathrm{C}(1)-\mathrm{Ru}(1)-\mathrm{C}(21)$ & $82.08(10)$ \\
\hline $\mathrm{N}(1)-\mathrm{C}(4)$ & $1.432(3)$ & $\mathrm{C}(1)-\mathrm{Ru}(1)-\mathrm{C}(22)$ & $92.40(9)$ \\
\hline $\mathrm{N}(1)-\mathrm{C}(2)$ & $1.471(3)$ & $\mathrm{C}(21)-\mathrm{Ru}(1)-\mathrm{C}(22)$ & $81.43(10)$ \\
\hline $\mathrm{N}(2)-\mathrm{C}(1)$ & $1.361(3)$ & $\mathrm{C}(1)-\mathrm{Ru}(1)-\mathrm{C}(23)$ & $99.58(9)$ \\
\hline $\mathrm{N}(2)-\mathrm{C}(13)$ & $1.432(3)$ & $\mathrm{C}(21)-\mathrm{Ru}(1)-\mathrm{C}(23)$ & $120.55(10)$ \\
\hline $\mathrm{N}(2)-\mathrm{C}(3)$ & $1.470(3)$ & $\mathrm{C}(22)-\mathrm{Ru}(1)-\mathrm{C}(23)$ & $39.21(10)$ \\
\hline $\mathrm{C}(2)-\mathrm{C}(3)$ & $1.506(4)$ & $\mathrm{C}(1)-\mathrm{Ru}(1)-\mathrm{Cl}(1)$ & $101.39(7)$ \\
\hline $\mathrm{C}(2)-\mathrm{H}(2 \mathrm{~A})$ & $0.88(3)$ & $\mathrm{C}(21)-\mathrm{Ru}(1)-\mathrm{Cl}(1)$ & $144.76(6)$ \\
\hline $\mathrm{C}(2)-\mathrm{H}(2 \mathrm{~B})$ & $0.94(4)$ & $\mathrm{C}(22)-\mathrm{Ru}(1)-\mathrm{Cl}(1)$ & $132.79(8)$ \\
\hline $\mathrm{C}(3)-\mathrm{H}(3 \mathrm{~A})$ & $0.88(3)$ & $\mathrm{C}(23)-\mathrm{Ru}(1)-\mathrm{Cl}(1)$ & $93.71(8)$ \\
\hline $\mathrm{C}(3)-\mathrm{H}(3 \mathrm{~B})$ & $1.02(3)$ & $\mathrm{C}(1)-\mathrm{Ru}(1)-\mathrm{Cl}(1) \# 1$ & $170.94(7)$ \\
\hline $\mathrm{C}(4)-\mathrm{C}(5)$ & $1.398(3)$ & $\mathrm{C}(21)-\mathrm{Ru}(1)-\mathrm{Cl}(1) \# 1$ & $89.68(7)$ \\
\hline $\mathrm{C}(4)-\mathrm{C}(9)$ & $1.411(3)$ & $\mathrm{C}(22)-\mathrm{Ru}(1)-\mathrm{Cl}(1) \# 1$ & $90.07(6)$ \\
\hline$C(5)-C(6)$ & $1.380(3)$ & $\mathrm{C}(23)-\mathrm{Ru}(1)-\mathrm{Cl}(1) \# 1$ & $87.82(6)$ \\
\hline$C(5)-C(10)$ & $1.513(3)$ & $\mathrm{Cl}(1)-\mathrm{Ru}(1)-\mathrm{Cl}(1) \# 1$ & $83.190(19)$ \\
\hline $\mathrm{C}(6)-\mathrm{C}(7)$ & $1.396(3)$ & $\mathrm{Ru}(1)-\mathrm{Cl}(1)-\mathrm{Ru}(1) \# 1$ & $96.809(19)$ \\
\hline $\mathrm{C}(6)-\mathrm{H}(6)$ & $0.82(2)$ & $\mathrm{C}(1)-\mathrm{N}(1)-\mathrm{C}(4)$ & $125.42(18)$ \\
\hline $\mathrm{C}(7)-\mathrm{C}(8)$ & $1.379(3)$ & $\mathrm{C}(1)-\mathrm{N}(1)-\mathrm{C}(2)$ & 111.87(19) \\
\hline $\mathrm{C}(7)-\mathrm{C}(11)$ & $1.499(4)$ & $\mathrm{C}(4)-\mathrm{N}(1)-\mathrm{C}(2)$ & $117.47(17)$ \\
\hline $\mathrm{C}(8)-\mathrm{C}(9)$ & $1.383(3)$ & $\mathrm{C}(1)-\mathrm{N}(2)-\mathrm{C}(13)$ & 117.14(17) \\
\hline $\mathrm{C}(8)-\mathrm{H}(8)$ & $0.85(2)$ & $\mathrm{C}(1)-\mathrm{N}(2)-\mathrm{C}(3)$ & $114.08(18)$ \\
\hline $\mathrm{C}(9)-\mathrm{C}(12)$ & $1.500(4)$ & $\mathrm{C}(13)-\mathrm{N}(2)-\mathrm{C}(3)$ & $125.8(2)$ \\
\hline $\mathrm{C}(10)-\mathrm{H}(10 \mathrm{~A})$ & $0.93(3)$ & $\mathrm{N}(2)-\mathrm{C}(1)-\mathrm{N}(1)$ & $106.28(18)$ \\
\hline $\mathrm{C}(10)-\mathrm{H}(10 \mathrm{~B})$ & $0.91(3)$ & $\mathrm{N}(2)-\mathrm{C}(1)-\mathrm{Ru}(1)$ & $113.79(14)$ \\
\hline $\mathrm{C}(10)-\mathrm{H}(10 \mathrm{C})$ & $0.99(3)$ & $\mathrm{N}(1)-\mathrm{C}(1)-\mathrm{Ru}(1)$ & $138.88(16)$ \\
\hline $\mathrm{C}(11)-\mathrm{H}(11 \mathrm{~A})$ & $0.91(3)$ & $\mathrm{N}(1)-\mathrm{C}(2)-\mathrm{C}(3)$ & 104.26(19) \\
\hline $\mathrm{C}(11)-\mathrm{H}(11 \mathrm{~B})$ & $0.99(3)$ & $\mathrm{N}(1)-\mathrm{C}(2)-\mathrm{H}(2 \mathrm{~A})$ & $105.9(18)$ \\
\hline $\mathrm{C}(11)-\mathrm{H}(11 \mathrm{C})$ & $0.89(3)$ & $\mathrm{C}(3)-\mathrm{C}(2)-\mathrm{H}(2 \mathrm{~A})$ & 116.6(19) \\
\hline $\mathrm{C}(12)-\mathrm{H}(12 \mathrm{~A})$ & $0.96(3)$ & $\mathrm{N}(1)-\mathrm{C}(2)-\mathrm{H}(2 \mathrm{~B})$ & $109(2)$ \\
\hline $\mathrm{C}(12)-\mathrm{H}(12 \mathrm{~B})$ & $0.90(2)$ & $\mathrm{C}(3)-\mathrm{C}(2)-\mathrm{H}(2 \mathrm{~B})$ & $115(2)$ \\
\hline $\mathrm{C}(12)-\mathrm{H}(12 \mathrm{C})$ & $0.89(3)$ & $\mathrm{H}(2 \mathrm{~A})-\mathrm{C}(2)-\mathrm{H}(2 \mathrm{~B})$ & $106(3)$ \\
\hline$C(13)-C(14)$ & $1.400(3)$ & $\mathrm{N}(2)-\mathrm{C}(3)-\mathrm{C}(2)$ & $101.3(2)$ \\
\hline $\mathrm{C}(13)-\mathrm{C}(18)$ & $1.403(3)$ & $\mathrm{N}(2)-\mathrm{C}(3)-\mathrm{H}(3 \mathrm{~A})$ & $109(2)$ \\
\hline$C(14)-C(15)$ & $1.392(3)$ & $\mathrm{C}(2)-\mathrm{C}(3)-\mathrm{H}(3 \mathrm{~A})$ & $114(2)$ \\
\hline C(14)-C(19) & $1.487(4)$ & $\mathrm{N}(2)-\mathrm{C}(3)-\mathrm{H}(3 \mathrm{~B})$ & $106.7(14)$ \\
\hline$C(15)-C(16)$ & $1.383(4)$ & $\mathrm{C}(2)-\mathrm{C}(3)-\mathrm{H}(3 \mathrm{~B})$ & $106.2(14)$ \\
\hline $\mathrm{C}(15)-\mathrm{H}(15)$ & $0.86(3)$ & $\mathrm{H}(3 \mathrm{~A})-\mathrm{C}(3)-\mathrm{H}(3 \mathrm{~B})$ & 119(3) \\
\hline$C(16)-C(17)$ & $1.368(3)$ & $C(5)-C(4)-C(9)$ & $120.7(2)$ \\
\hline$C(16)-C(20)$ & $1.514(3)$ & $\mathrm{C}(5)-\mathrm{C}(4)-\mathrm{N}(1)$ & $120.10(19)$ \\
\hline $\mathrm{C}(17)-\mathrm{C}(18)$ & $1.406(3)$ & $\mathrm{C}(9)-\mathrm{C}(4)-\mathrm{N}(1)$ & $118.8(2)$ \\
\hline $\mathrm{C}(17)-\mathrm{H}(17)$ & $0.84(2)$ & $C(6)-C(5)-C(4)$ & $118.4(2)$ \\
\hline $\mathrm{C}(18)-\mathrm{C}(21)$ & $1.485(3)$ & $C(6)-C(5)-C(10)$ & $120.7(2)$ \\
\hline $\mathrm{C}(19)-\mathrm{H}(19 \mathrm{~A})$ & $0.98(3)$ & $\mathrm{C}(4)-\mathrm{C}(5)-\mathrm{C}(10)$ & $120.9(2)$ \\
\hline C(19)-H(19B) & $0.96(4)$ & $C(5)-C(6)-C(7)$ & $122.6(2)$ \\
\hline C(19)-H(19C) & $1.00(4)$ & $\mathrm{C}(5)-\mathrm{C}(6)-\mathrm{H}(6)$ & $118.5(17)$ \\
\hline $\mathrm{C}(20)-\mathrm{H}(20 \mathrm{~A})$ & $0.89(4)$ & $\mathrm{C}(7)-\mathrm{C}(6)-\mathrm{H}(6)$ & $118.9(17)$ \\
\hline $\mathrm{C}(20)-\mathrm{H}(20 \mathrm{~B})$ & $0.89(4)$ & $C(8)-C(7)-C(6)$ & $117.3(2)$ \\
\hline $\mathrm{C}(20)-\mathrm{H}(20 \mathrm{C})$ & $1.03(4)$ & $\mathrm{C}(8)-\mathrm{C}(7)-\mathrm{C}(11)$ & $121.4(2)$ \\
\hline $\mathrm{C}(21)-\mathrm{H}(21 \mathrm{~A})$ & $1.07(3)$ & $\mathrm{C}(6)-\mathrm{C}(7)-\mathrm{C}(11)$ & $121.4(2)$ \\
\hline
\end{tabular}




\begin{tabular}{|c|c|}
\hline$C(7)-C(8)-C(9)$ & $123.1(2)$ \\
\hline $\mathrm{C}(7)-\mathrm{C}(8)-\mathrm{H}(8)$ & $121.7(17)$ \\
\hline $\mathrm{C}(9)-\mathrm{C}(8)-\mathrm{H}(8)$ & $115.1(17)$ \\
\hline$C(8)-C(9)-C(4)$ & $117.8(2)$ \\
\hline $\mathrm{C}(8)-\mathrm{C}(9)-\mathrm{C}(12)$ & $120.5(2)$ \\
\hline$C(4)-C(9)-C(12)$ & $121.6(2)$ \\
\hline $\mathrm{C}(5)-\mathrm{C}(10)-\mathrm{H}(10 \mathrm{~A})$ & $108.8(15)$ \\
\hline $\mathrm{C}(5)-\mathrm{C}(10)-\mathrm{H}(10 \mathrm{~B})$ & 109.9(16) \\
\hline $\mathrm{H}(10 \mathrm{~A})-\mathrm{C}(10)-\mathrm{H}(10 \mathrm{~B})$ & $105(2)$ \\
\hline $\mathrm{C}(5)-\mathrm{C}(10)-\mathrm{H}(10 \mathrm{C})$ & $111.9(14)$ \\
\hline $\mathrm{H}(10 \mathrm{~A})-\mathrm{C}(10)-\mathrm{H}(10 \mathrm{C})$ & $114(2)$ \\
\hline $\mathrm{H}(10 \mathrm{~B})-\mathrm{C}(10)-\mathrm{H}(10 \mathrm{C})$ & $107(2)$ \\
\hline $\mathrm{C}(7)-\mathrm{C}(11)-\mathrm{H}(11 \mathrm{~A})$ & $111.0(19)$ \\
\hline $\mathrm{C}(7)-\mathrm{C}(11)-\mathrm{H}(11 \mathrm{~B})$ & 110.3(19) \\
\hline $\mathrm{H}(11 \mathrm{~A})-\mathrm{C}(11)-\mathrm{H}(11 \mathrm{~B})$ & $108(3)$ \\
\hline $\mathrm{C}(7)-\mathrm{C}(11)-\mathrm{H}(11 \mathrm{C})$ & $107(2)$ \\
\hline $\mathrm{H}(11 \mathrm{~A})-\mathrm{C}(11)-\mathrm{H}(11 \mathrm{C})$ & $110(3)$ \\
\hline $\mathrm{H}(11 \mathrm{~B})-\mathrm{C}(11)-\mathrm{H}(11 \mathrm{C})$ & 111(3) \\
\hline $\mathrm{C}(9)-\mathrm{C}(12)-\mathrm{H}(12 \mathrm{~A})$ & 111.1(17) \\
\hline $\mathrm{C}(9)-\mathrm{C}(12)-\mathrm{H}(12 \mathrm{~B})$ & $113.0(16)$ \\
\hline $\mathrm{H}(12 \mathrm{~A})-\mathrm{C}(12)-\mathrm{H}(12 \mathrm{~B})$ & $105(2)$ \\
\hline $\mathrm{C}(9)-\mathrm{C}(12)-\mathrm{H}(12 \mathrm{C})$ & 111.4(19) \\
\hline $\mathrm{H}(12 \mathrm{~A})-\mathrm{C}(12)-\mathrm{H}(12 \mathrm{C})$ & $107(2)$ \\
\hline $\mathrm{H}(12 \mathrm{~B})-\mathrm{C}(12)-\mathrm{H}(12 \mathrm{C})$ & $109(2)$ \\
\hline $\mathrm{C}(14)-\mathrm{C}(13)-\mathrm{C}(18)$ & $121.6(2)$ \\
\hline $\mathrm{C}(14)-\mathrm{C}(13)-\mathrm{N}(2)$ & $120.1(2)$ \\
\hline $\mathrm{C}(18)-\mathrm{C}(13)-\mathrm{N}(2)$ & $118.20(19)$ \\
\hline $\mathrm{C}(15)-\mathrm{C}(14)-\mathrm{C}(13)$ & $117.0(2)$ \\
\hline C(15)-C(14)-C(19) & $120.9(3)$ \\
\hline $\mathrm{C}(13)-\mathrm{C}(14)-\mathrm{C}(19)$ & $122.1(2)$ \\
\hline $\mathrm{C}(16)-\mathrm{C}(15)-\mathrm{C}(14)$ & $123.2(2)$ \\
\hline $\mathrm{C}(16)-\mathrm{C}(15)-\mathrm{H}(15)$ & $118.0(16)$ \\
\hline $\mathrm{C}(14)-\mathrm{C}(15)-\mathrm{H}(15)$ & 118.6(16) \\
\hline $\mathrm{C}(17)-\mathrm{C}(16)-\mathrm{C}(15)$ & $118.1(2)$ \\
\hline $\mathrm{C}(17)-\mathrm{C}(16)-\mathrm{C}(20)$ & $121.2(3)$ \\
\hline$C(15)-C(16)-C(20)$ & $120.7(3)$ \\
\hline $\mathrm{C}(16)-\mathrm{C}(17)-\mathrm{C}(18)$ & $122.3(2)$ \\
\hline $\mathrm{C}(16)-\mathrm{C}(17)-\mathrm{H}(17)$ & 120.1(17) \\
\hline $\mathrm{C}(18)-\mathrm{C}(17)-\mathrm{H}(17)$ & $117.5(17)$ \\
\hline $\mathrm{C}(13)-\mathrm{C}(18)-\mathrm{C}(17)$ & $117.5(2)$ \\
\hline $\mathrm{C}(13)-\mathrm{C}(18)-\mathrm{C}(21)$ & 119.49(19) \\
\hline $\mathrm{C}(17)-\mathrm{C}(18)-\mathrm{C}(21)$ & $122.9(2)$ \\
\hline $\mathrm{C}(14)-\mathrm{C}(19)-\mathrm{H}(19 \mathrm{~A})$ & 108.4(18) \\
\hline C(14)-C(19)-H(19B) & 118.9(19) \\
\hline H(19A)-C(19)-H(19B) & 101(3) \\
\hline C(14)-C(19)-H(19C) & $111(2)$ \\
\hline $\mathrm{H}(19 \mathrm{~A})-\mathrm{C}(19)-\mathrm{H}(19 \mathrm{C})$ & 119(3) \\
\hline H(19B)-C(19)-H(19C) & $99(3)$ \\
\hline $\mathrm{C}(16)-\mathrm{C}(20)-\mathrm{H}(20 \mathrm{~A})$ & 109(3) \\
\hline $\mathrm{C}(16)-\mathrm{C}(20)-\mathrm{H}(20 \mathrm{~B})$ & $110(2)$ \\
\hline $\mathrm{H}(20 \mathrm{~A})-\mathrm{C}(20)-\mathrm{H}(20 \mathrm{~B})$ & $106(3)$ \\
\hline $\mathrm{C}(16)-\mathrm{C}(20)-\mathrm{H}(20 \mathrm{C})$ & $113(2)$ \\
\hline $\mathrm{H}(20 \mathrm{~A})-\mathrm{C}(20)-\mathrm{H}(20 \mathrm{C})$ & $108(3)$ \\
\hline $\mathrm{H}(20 \mathrm{~B})-\mathrm{C}(20)-\mathrm{H}(20 \mathrm{C})$ & $110(3)$ \\
\hline $\mathrm{C}(18)-\mathrm{C}(21)-\mathrm{Ru}(1)$ & $86.08(15)$ \\
\hline $\mathrm{C}(18)-\mathrm{C}(21)-\mathrm{H}(21 \mathrm{~A})$ & 119.9(13) \\
\hline $\mathrm{Ru}(1)-\mathrm{C}(21)-\mathrm{H}(21 \mathrm{~A})$ & 118.2(13) \\
\hline $\mathrm{C}(18)-\mathrm{C}(21)-\mathrm{H}(21 \mathrm{~B})$ & 112.9(19) \\
\hline $\mathrm{Ru}(1)-\mathrm{C}(21)-\mathrm{H}(21 \mathrm{~B})$ & $116(2)$ \\
\hline
\end{tabular}

$\begin{array}{lc}\mathrm{H}(21 \mathrm{~A})-\mathrm{C}(21)-\mathrm{H}(21 \mathrm{~B}) & 104(2) \\ \mathrm{C}(23)-\mathrm{C}(22)-\mathrm{Ru}(1) & 70.58(13) \\ \mathrm{C}(23)-\mathrm{C}(22)-\mathrm{H}(22 \mathrm{~A}) & 116.7(15) \\ \mathrm{Ru}(1)-\mathrm{C}(22)-\mathrm{H}(22 \mathrm{~A}) & 112.9(14) \\ \mathrm{C}(23)-\mathrm{C}(22)-\mathrm{H}(22 \mathrm{~B}) & 121.8(16) \\ \mathrm{Ru}(1)-\mathrm{C}(22)-\mathrm{H}(22 \mathrm{~B}) & 116.4(15) \\ \mathrm{H}(22 \mathrm{~A})-\mathrm{C}(22)-\mathrm{H}(22 \mathrm{~B}) & 112(2) \\ \mathrm{C}(22)-\mathrm{C}(23)-\mathrm{Ru}(1) & 70.20(13) \\ \mathrm{C}(22)-\mathrm{C}(23)-\mathrm{H}(23 \mathrm{~A}) & 120.7(16) \\ \mathrm{Ru}(1)-\mathrm{C}(23)-\mathrm{H}(23 \mathrm{~A}) & 117.0(15) \\ \mathrm{C}(22)-\mathrm{C}(23)-\mathrm{H}(23 \mathrm{~B}) & 120.0(13) \\ \mathrm{Ru}(1)-\mathrm{C}(23)-\mathrm{H}(23 \mathrm{~B}) & 112.3(12) \\ \mathrm{H}(23 \mathrm{~A})-\mathrm{C}(23)-\mathrm{H}(23 \mathrm{~B}) & 111(2)\end{array}$

Symmetry transformations used to generate equivalent atoms: \#1-x+1,-y+1,-z+1. 
Table S.12. Anisotropic displacement parameters $\left(\AA^{2} \times 1^{4}\right)$ for 21 (CCDC 612720). The anisotropic displacement factor exponent takes the form: $-2 \pi^{2}\left[h^{2} a^{* 2} U^{11}+\ldots+2 h k a^{*} b^{*} U^{12}\right]$

\begin{tabular}{llllllr}
\hline & $\mathrm{U}^{11}$ & $\mathrm{U}^{22}$ & $\mathrm{U}^{33}$ & $\mathrm{U}^{23}$ & $\mathrm{U}^{13}$ & $\mathrm{U}^{12}$ \\
\hline $\mathrm{Ru}(1)$ & $155(1)$ & $234(1)$ & $127(1)$ & $-15(1)$ & $28(1)$ & $100(1)$ \\
$\mathrm{Cl}(1)$ & $175(2)$ & $255(3)$ & $185(2)$ & $-19(2)$ & $70(2)$ & $85(2)$ \\
$\mathrm{N}(1)$ & $290(10)$ & $248(11)$ & $165(8)$ & $-4(8)$ & $57(7)$ & $177(9)$ \\
$\mathrm{N}(2)$ & $267(10)$ & $370(12)$ & $188(9)$ & $-7(8)$ & $39(7)$ & $232(10)$ \\
$\mathrm{C}(1)$ & $216(11)$ & $219(13)$ & $168(10)$ & $15(9)$ & $41(8)$ & $115(10)$ \\
$\mathrm{C}(2)$ & $570(19)$ & $540(20)$ & $264(13)$ & $-10(14)$ & $68(13)$ & $450(18)$ \\
$\mathrm{C}(3)$ & $393(16)$ & $373(17)$ & $267(12)$ & $29(11)$ & $94(11)$ & $280(14)$ \\
$\mathrm{C}(4)$ & $286(12)$ & $241(13)$ & $125(9)$ & $-11(9)$ & $76(8)$ & $168(10)$ \\
$\mathrm{C}(5)$ & $254(11)$ & $217(13)$ & $181(10)$ & $-7(9)$ & $82(8)$ & $123(10)$ \\
$\mathrm{C}(6)$ & $344(14)$ & $184(14)$ & $267(12)$ & $81(10)$ & $151(10)$ & $124(11)$ \\
$\mathrm{C}(7)$ & $288(12)$ & $296(14)$ & $203(10)$ & $59(10)$ & $98(9)$ & $179(11)$ \\
$\mathrm{C}(8)$ & $225(12)$ & $243(14)$ & $202(11)$ & $-20(10)$ & $50(9)$ & $101(11)$ \\
$\mathrm{C}(9)$ & $255(11)$ & $219(13)$ & $197(10)$ & $1(9)$ & $99(9)$ & $130(10)$ \\
$\mathrm{C}(10)$ & $292(13)$ & $295(15)$ & $219(12)$ & $6(11)$ & $70(10)$ & $76(12)$ \\
$\mathrm{C}(11)$ & $349(16)$ & $401(19)$ & $361(15)$ & $175(14)$ & $103(12)$ & $181(15)$ \\
$\mathrm{C}(12)$ & $317(14)$ & $270(15)$ & $248(13)$ & $24(11)$ & $80(10)$ & $146(12)$ \\
$\mathrm{C}(13)$ & $263(12)$ & $343(15)$ & $210(11)$ & $40(10)$ & $40(9)$ & $193(11)$ \\
$\mathrm{C}(14)$ & $277(13)$ & $553(19)$ & $330(13)$ & $27(13)$ & $20(10)$ & $258(14)$ \\
$\mathrm{C}(15)$ & $275(14)$ & $580(20)$ & $317(14)$ & $1(13)$ & $-74(11)$ & $231(15)$ \\
$\mathrm{C}(16)$ & $392(15)$ & $371(16)$ & $202(11)$ & $49(11)$ & $-32(10)$ & $202(13)$ \\
$\mathrm{C}(17)$ & $335(13)$ & $351(15)$ & $180(11)$ & $78(10)$ & $83(10)$ & $189(12)$ \\
$\mathrm{C}(18)$ & $251(12)$ & $285(14)$ & $192(10)$ & $45(9)$ & $19(8)$ & $148(11)$ \\
$\mathrm{C}(19)$ & $298(18)$ & $1110(40)$ & $550(20)$ & $-30(20)$ & $60(15)$ & $360(20)$ \\
$\mathrm{C}(20)$ & $500(20)$ & $520(20)$ & $220(13)$ & $5(13)$ & $-48(12)$ & $249(18)$ \\
$\mathrm{C}(21)$ & $224(12)$ & $283(15)$ & $204(11)$ & $54(10)$ & $61(9)$ & $95(11)$ \\
$\mathrm{C}(22)$ & $163(11)$ & $340(15)$ & $203(11)$ & $-38(10)$ & $8(8)$ & $122(11)$ \\
$\mathrm{C}(23)$ & $234(12)$ & $359(16)$ & $199(11)$ & $-39(10)$ & $-2(9)$ & $202(12)$ \\
& & & & & & \\
\hline & & & & & &
\end{tabular}


Table S.13. Hydrogen coordinates $\left(x 1^{4}\right)$ and isotropic displacement parameters $\left(\AA^{2} \times 10^{3}\right)$ for 21 (CCDC 612720).

\begin{tabular}{|c|c|c|c|c|}
\hline & $\mathrm{x}$ & $\mathrm{y}$ & $\mathrm{z}$ & $\mathrm{U}_{\text {iso }}$ \\
\hline $\mathrm{H}(2 \mathrm{~A})$ & $5170(30)$ & $10500(30)$ & $8700(20)$ & $35(8)$ \\
\hline $\mathrm{H}(2 \mathrm{~B})$ & $3880(40)$ & $9200(40)$ & $8820(30)$ & $82(13)$ \\
\hline $\mathrm{H}(3 \mathrm{~A})$ & $2580(40)$ & $9050(30)$ & $7010(30)$ & $54(9)$ \\
\hline $\mathrm{H}(3 \mathrm{~B})$ & $4200(30)$ & $10280(30)$ & $6830(20)$ & $33(7)$ \\
\hline $\mathrm{H}(6)$ & $5630(30)$ & $6470(30)$ & $10640(20)$ & $17(6)$ \\
\hline $\mathrm{H}(8)$ & $9170(30)$ & $10250(30)$ & $11210(20)$ & $22(6)$ \\
\hline $\mathrm{H}(10 \mathrm{~A})$ & $3830(30)$ & $5770(30)$ & $7950(20)$ & $31(7)$ \\
\hline $\mathrm{H}(10 \mathrm{~B})$ & $3130(30)$ & $6560(30)$ & $8560(20)$ & $26(7)$ \\
\hline $\mathrm{H}(10 \mathrm{C})$ & $3260(30)$ & $5440(30)$ & $9130(20)$ & $28(7)$ \\
\hline $\mathrm{H}(11 \mathrm{~A})$ & $7610(30)$ & $7450(30)$ & $12520(20)$ & $46(9)$ \\
\hline $\mathrm{H}(11 \mathrm{~B})$ & $8890(40)$ & $9040(40)$ & $12880(30)$ & $64(10)$ \\
\hline $\mathrm{H}(11 \mathrm{C})$ & $8980(40)$ & $7800(30)$ & $12040(30)$ & $56(10)$ \\
\hline $\mathrm{H}(12 \mathrm{~A})$ & $8120(30)$ & $11840(30)$ & $9870(20)$ & $41(8)$ \\
\hline $\mathrm{H}(12 \mathrm{~B})$ & $8180(30)$ & $11090(30)$ & $8730(20)$ & $25(6)$ \\
\hline $\mathrm{H}(12 \mathrm{C})$ & $9470(30)$ & $11590(30)$ & $9760(20)$ & $39(8)$ \\
\hline $\mathrm{H}(15)$ & $310(30)$ & $5890(30)$ & $2910(20)$ & $29(7)$ \\
\hline $\mathrm{H}(17)$ & $4570(30)$ & $7010(30)$ & $2890(20)$ & $27(7)$ \\
\hline $\mathrm{H}(19 \mathrm{~A})$ & $620(30)$ & $6450(30)$ & $5820(30)$ & $47(9)$ \\
\hline $\mathrm{H}(19 \mathrm{~B})$ & $-600(40)$ & $6180(40)$ & $4760(30)$ & $67(10)$ \\
\hline $\mathrm{H}(19 \mathrm{C})$ & 430(40) & $7770(40)$ & $5330(30)$ & $82(13)$ \\
\hline $\mathrm{H}(20 \mathrm{~A})$ & $840(50)$ & $5320(40)$ & $1050(40)$ & $98(15)$ \\
\hline $\mathrm{H}(20 \mathrm{~B})$ & $1850(40)$ & $4730(40)$ & $1210(30)$ & $78(13)$ \\
\hline $\mathrm{H}(20 \mathrm{C})$ & $2480(40)$ & $6170(40)$ & $840(30)$ & $86(13)$ \\
\hline $\mathrm{H}(21 \mathrm{~A})$ & $6600(30)$ & $9660(30)$ & $5700(20)$ & $32(7)$ \\
\hline $\mathrm{H}(21 \mathrm{~B})$ & $6730(30)$ & $8670(30)$ & $4650(30)$ & $49(9)$ \\
\hline $\mathrm{H}(22 \mathrm{~A})$ & $8650(30)$ & $8320(30)$ & $6280(20)$ & $31(7)$ \\
\hline $\mathrm{H}(22 \mathrm{~B})$ & $8200(30)$ & $9140(30)$ & $7370(20)$ & $39(7)$ \\
\hline $\mathrm{H}(23 \mathrm{~A})$ & $7150(30)$ & $6880(30)$ & $7940(20)$ & $41(8)$ \\
\hline $\mathrm{H}(23 \mathrm{~B})$ & $7580(20)$ & $6170(20)$ & $6823(18)$ & $11(5)$ \\
\hline
\end{tabular}




\section{Crystal Structure Analysis of 25}

\section{Contents}

Table S.15. Crystal data

Figures Figures for publication

Table S.16. Atomic Coordinates

Table S.17. Selected bond distances and angles

Table S.18. Full bond distances and angles (for deposit)

Table S.19. Anisotropic displacement parameters

Table S.20. Hydrogen atomic coordinates

Table S.21. Observed and calculated structure factors (for deposit)

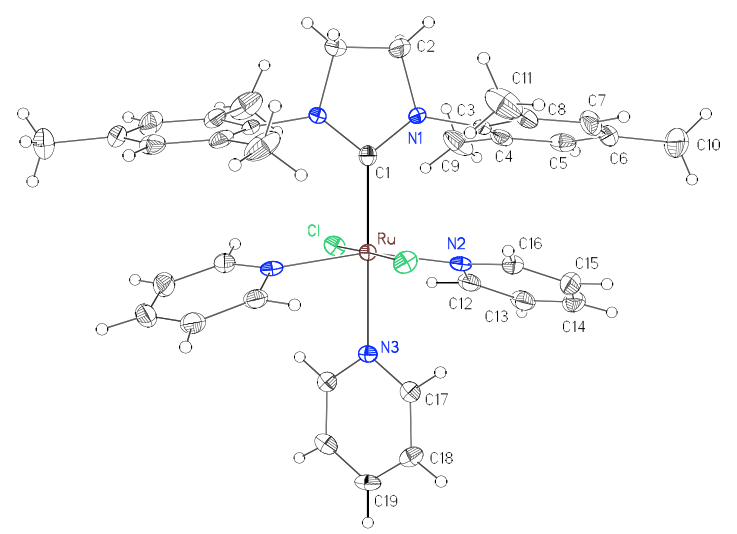

Note: Crystallographic data have been deposited at the CCDC, 12 Union Road, Cambridge CB2 1EZ, UK and copies can be obtained on request, free of charge, by quoting the publication citation and the deposition number 177531. 
Table S.15. Crystal data and structure refinement for 25 (CCDC 177531).

Empirical formula

Formula weight

Crystallization Solvent

Crystal Habit

Crystal size

Crystal color

Preliminary Photos

Type of diffractometer

Wavelength

Data Collection Temperature

$\theta$ range for 15081 reflections used in lattice determination

Unit cell dimensions

Volume

Z

Crystal system

Space group

Density (calculated)

$\mathrm{F}(000)$

Data collection program

$\theta$ range for data collection

Completeness to $\theta=28.26^{\circ}$

Index ranges

Data collection scan type

Data reduction program

Reflections collected

Independent reflections

Absorption coefficient

Absorption correction

Max. and min. transmission
$\mathrm{C}_{36} \mathrm{H}_{41} \mathrm{Cl}_{2} \mathrm{~N}_{5} \mathrm{Ru}$

715.71

Hexanes

Plate

$0.33 \times 0.28 \times 0.08 \mathrm{~mm}^{3}$

Orange

\section{Data Collection}

Rotation

Bruker SMART 1000 CCD

$0.71073 \AA$ MoK $\alpha$

98(2) K

2.35 to $28.09^{\circ}$

$\mathrm{a}=11.3376(7) \AA$

$\mathrm{b}=13.3755(8) \AA$

$c=21.4203(14) \AA$

3248.3(4) $\AA^{3}$

4

Orthorhombic

Pben

$1.463 \mathrm{Mg} / \mathrm{m}^{3}$

1480

Bruker SMART v.5.054

1.90 to $28.26^{\circ}$

$96.5 \%$

$-14 \leq \mathrm{h} \leq 15,-17 \leq \mathrm{k} \leq 17,-28 \leq 1 \leq 27$

$\omega$ scans at $5 \phi$ settings

Bruker SAINT v6.022

44246

$3886\left[\mathrm{R}_{\mathrm{int}}=0.0635\right]$

$0.681 \mathrm{~mm}^{-1}$

None

0.9475 and 0.8064 


\section{Table S.15 (cont.)}

\section{Structure solution and Refinement}

Structure solution program

Primary solution method

Secondary solution method

Hydrogen placement

Structure refinement program

Refinement method

Data / restraints / parameters

Treatment of hydrogen atoms

Goodness-of-fit on $\mathrm{F}^{2}$

Final R indices [I $>2 \sigma(\mathrm{I}), 2923$ reflections]

$\mathrm{R}$ indices (all data)

Type of weighting scheme used

Weighting scheme used

Max shift/error

Average shift/error

Largest diff. peak and hole
SHELXS-97 (Sheldrick, 1990)

Direct methods

Difference Fourier map

Difference Fourier map

SHELXL-97 (Sheldrick, 1997)

Full matrix least-squares on $\mathrm{F}^{2}$

3886 / 0 / 283

Unrestrained

1.716

$\mathrm{R} 1=0.0320, w \mathrm{R} 2=0.0498$

$\mathrm{R} 1=0.0481, w \mathrm{R} 2=0.0509$

Sigma

$w=1 / \sigma^{2}\left(\mathrm{Fo}^{2}\right)$

0.006

0.000

1.301 and -0.675 e. $\AA^{-3}$

\section{Special Refinement Details}

Refinement of $\mathrm{F}^{2}$ against ALL reflections. The weighted R-factor $(w \mathrm{R})$ and goodness of fit $(\mathrm{S})$ are based on $\mathrm{F}^{2}$, conventional R-factors $(R)$ are based on $F$, with $F$ set to zero for negative $F^{2}$. The threshold expression of $F^{2}>2 \sigma\left(F^{2}\right)$ is used only for calculating R-factors $(\mathrm{gt})$ etc. and is not relevant to the choice of reflections for refinement. R-factors based on $\mathrm{F}^{2}$ are statistically about twice as large as those based on F, and R-factors based on ALL data will be even larger.

All esds (except the esd in the dihedral angle between two l.s. planes) are estimated using the full covariance matrix. The cell esds are taken into account individually in the estimation of esds in distances, angles and torsion angles; correlations between esds in cell parameters are only used when they are defined by crystal symmetry. An approximate (isotropic) treatment of cell esds is used for estimating esds involving l.s. planes. 


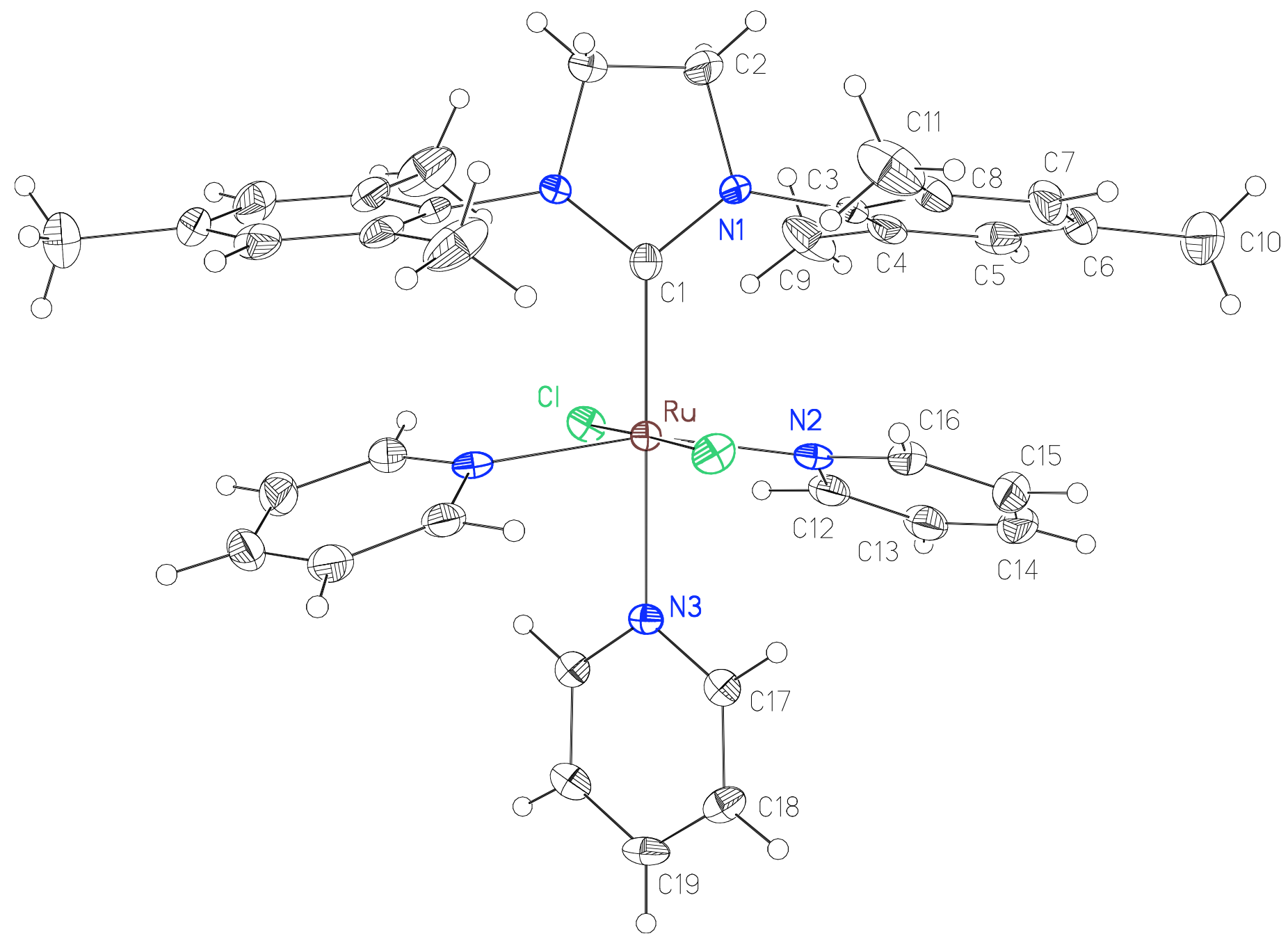



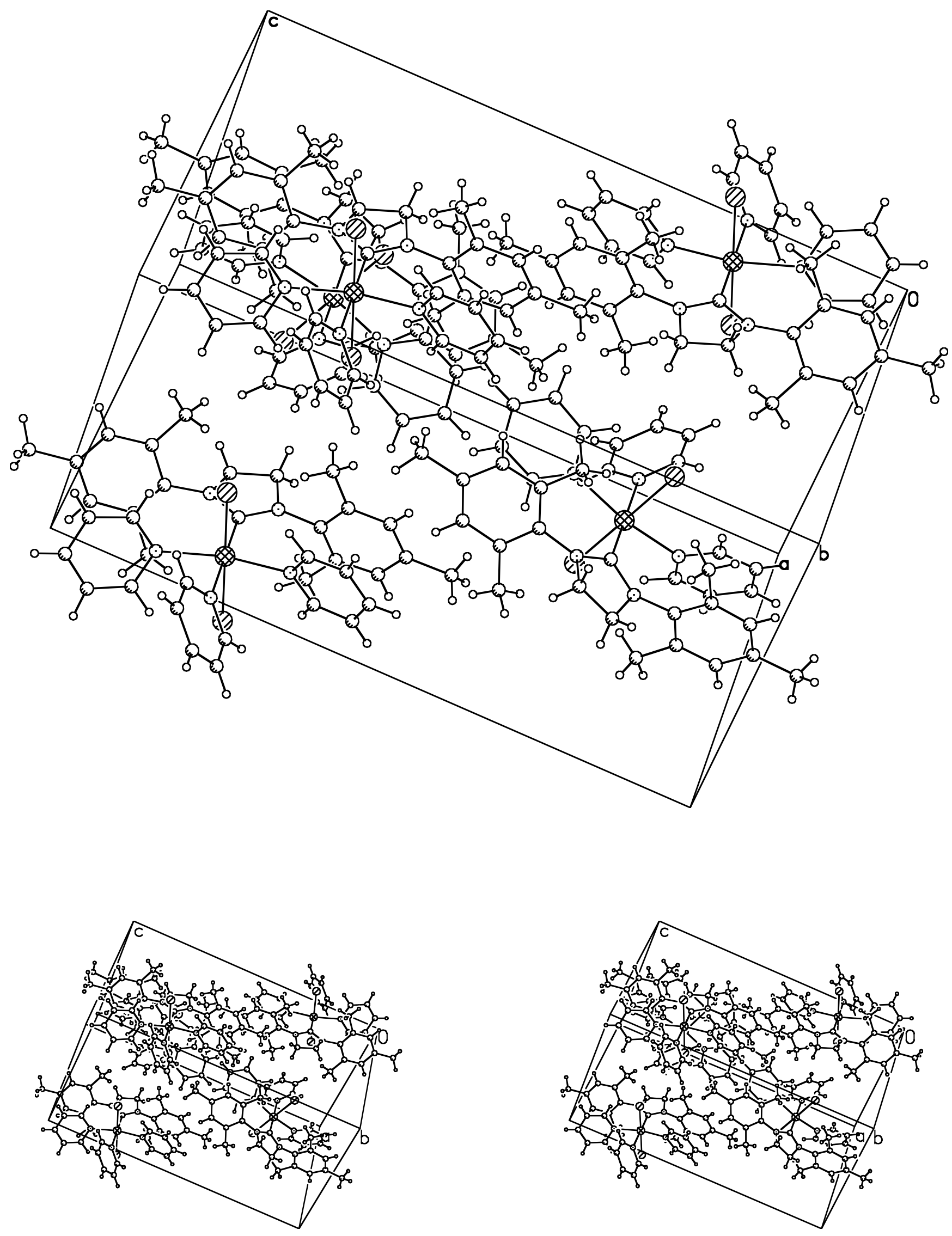
Table S.16. Atomic coordinates $\left(x \mathbf{1 0}^{4}\right)$ and equivalent isotropic displacement parameters $\left(\AA^{2} \mathbf{x}\right.$ $\left.1^{3}\right)$ for 25 (CCDC 177531). $U(e q)$ is defined as the trace of the orthogonalized $U^{i j}$ tensor.

\begin{tabular}{|c|c|c|c|c|}
\hline & $\mathrm{X}$ & $\mathrm{y}$ & $\mathrm{z}$ & $\mathrm{U}_{\mathrm{eq}}$ \\
\hline $\mathrm{Ru}$ & 10000 & $1639(1)$ & 2500 & $12(1)$ \\
\hline $\mathrm{Cl}$ & $7966(1)$ & $1621(1)$ & $2874(1)$ & $19(1)$ \\
\hline $\mathrm{N}(1)$ & $9783(2)$ & $3805(1)$ & $2009(1)$ & $27(1)$ \\
\hline $\mathrm{N}(2)$ & $9421(2)$ & $1420(1)$ & $1566(1)$ & $16(1)$ \\
\hline $\mathrm{N}(3)$ & 10000 & $13(2)$ & 2500 & $13(1)$ \\
\hline $\mathrm{C}(1)$ & 10000 & $3174(2)$ & 2500 & $16(1)$ \\
\hline $\mathrm{C}(2)$ & $9723(4)$ & $4869(2)$ & $2188(1)$ & $58(1)$ \\
\hline $\mathrm{C}(3)$ & $9594(2)$ & $3622(1)$ & $1360(1)$ & $19(1)$ \\
\hline $\mathrm{C}(4)$ & $8462(2)$ & $3446(2)$ & $1134(1)$ & $21(1)$ \\
\hline$C(5)$ & $8316(2)$ & $3365(2)$ & 494(1) & $25(1)$ \\
\hline$C(6)$ & $9242(2)$ & $3482(2)$ & $79(1)$ & $27(1)$ \\
\hline $\mathrm{C}(7)$ & $10342(2)$ & $3687(2)$ & $322(1)$ & $28(1)$ \\
\hline $\mathrm{C}(8)$ & $10546(2)$ & $3762(2)$ & $955(1)$ & $22(1)$ \\
\hline $\mathrm{C}(9)$ & $7431(2)$ & $3351(3)$ & $1565(2)$ & $39(1)$ \\
\hline $\mathrm{C}(10)$ & $9079(4)$ & $3369(3)$ & $-617(1)$ & $53(1)$ \\
\hline $\mathrm{C}(11)$ & $11750(3)$ & $3977(2)$ & $1211(2)$ & $43(1)$ \\
\hline$C(12)$ & $8338(2)$ & $1034(2)$ & $1456(1)$ & $24(1)$ \\
\hline$C(13)$ & $7964(2)$ & 701(2) & 882(1) & $29(1)$ \\
\hline$C(14)$ & $8716(2)$ & $743(2)$ & $383(1)$ & $32(1)$ \\
\hline$C(15)$ & $9823(2)$ & $1133(2)$ & $477(1)$ & $29(1)$ \\
\hline$C(16)$ & $10130(2)$ & $1456(2)$ & $1064(1)$ & $23(1)$ \\
\hline $\mathrm{C}(17)$ & $10613(2)$ & $-515(2)$ & $2076(1)$ & $17(1)$ \\
\hline $\mathrm{C}(18)$ & $10634(2)$ & $-1544(2)$ & $2064(1)$ & $20(1)$ \\
\hline$C(19)$ & 10000 & $-2069(2)$ & 2500 & $21(1)$ \\
\hline
\end{tabular}


Table S.17. Selected bond lengths $[\AA ̊ \AA]$ and angles $\left[{ }^{\circ}\right]$ for 25 (CCDC 177531).

\begin{tabular}{lllc}
\hline $\mathrm{Ru}-\mathrm{C}(1)$ & $2.052(3)$ & $\mathrm{C}(1)-\mathrm{Ru}-\mathrm{N}(2)$ & $97.92(4)$ \\
$\mathrm{Ru}-\mathrm{N}(2)$ & $2.1265(16)$ & $\mathrm{C}(1)-\mathrm{Ru}-\mathrm{N}(2) \# 1$ & $97.92(4)$ \\
$\mathrm{Ru}-\mathrm{N}(2) \# 1$ & $2.1265(16)$ & $\mathrm{N}(2)-\mathrm{Ru}-\mathrm{N}(2) \# 1$ & $164.16(8)$ \\
$\mathrm{Ru}-\mathrm{N}(3)$ & $2.176(2)$ & $\mathrm{C}(1)-\mathrm{Ru}-\mathrm{N}(3)$ & 180.0 \\
$\mathrm{Ru}-\mathrm{Cl}$ & $2.4415(5)$ & $\mathrm{N}(2)-\mathrm{Ru}-\mathrm{N}(3)$ & $82.08(4)$ \\
$\mathrm{Ru}-\mathrm{Cl} \# 1$ & $2.4415(5)$ & $\mathrm{N}(2) \# 1-\mathrm{Ru}-\mathrm{N}(3)$ & $82.08(4)$ \\
& & $\mathrm{C}(1)-\mathrm{Ru}-\mathrm{Cl}$ & $90.573(13)$ \\
& & $\mathrm{N}(2)-\mathrm{Ru}-\mathrm{Cl}$ & $90.88(5)$ \\
& & $\mathrm{N}(2) \# 1-\mathrm{Ru}-\mathrm{Cl}$ & $88.96(5)$ \\
& & $\mathrm{N}(3)-\mathrm{Ru}-\mathrm{Cl}$ & $89.427(13)$ \\
& & $\mathrm{C}(1)-\mathrm{Ru}-\mathrm{Cl} \# 1$ & $90.573(13)$ \\
& & $\mathrm{N}(2)-\mathrm{Ru}-\mathrm{Cl} \# 1$ & $88.96(5)$ \\
& & $\mathrm{N}(2) \# 1-\mathrm{Ru}-\mathrm{Cl} \# 1$ & $90.88(5)$ \\
& & $\mathrm{N}(3)-\mathrm{Ru}-\mathrm{Cl} \# 1$ & $89.427(13)$ \\
& & $\mathrm{Cl}-\mathrm{Ru}-\mathrm{Cl} \# 1$ & $178.85(3)$
\end{tabular}

Symmetry transformations used to generate equivalent atoms:

\#1 - $\mathrm{x}+2, \mathrm{y},-\mathrm{z}+1 / 2$ 
Table S.18. Bond lengths $[\AA]$ and angles $\left[{ }^{\circ}\right]$ for 25 (CCDC 177531).

\begin{tabular}{|c|c|c|c|}
\hline $\mathrm{Ru}-\mathrm{C}(1)$ & $2.052(3)$ & $\mathrm{C}(1)-\mathrm{Ru}-\mathrm{N}(3)$ & 180.0 \\
\hline $\mathrm{Ru}-\mathrm{N}(2)$ & $2.1265(16)$ & $\mathrm{N}(2)-\mathrm{Ru}-\mathrm{N}(3)$ & $82.08(4)$ \\
\hline $\mathrm{Ru}-\mathrm{N}(2) \# 1$ & $2.1265(16)$ & $\mathrm{N}(2) \# 1-\mathrm{Ru}-\mathrm{N}(3)$ & $82.08(4)$ \\
\hline $\mathrm{Ru}-\mathrm{N}(3)$ & $2.176(2)$ & $\mathrm{C}(1)-\mathrm{Ru}-\mathrm{Cl}$ & $90.573(13)$ \\
\hline $\mathrm{Ru}-\mathrm{Cl}$ & $2.4415(5)$ & $\mathrm{N}(2)-\mathrm{Ru}-\mathrm{Cl}$ & $90.88(5)$ \\
\hline $\mathrm{Ru}-\mathrm{Cl} \# 1$ & $2.4415(5)$ & $\mathrm{N}(2) \# 1-\mathrm{Ru}-\mathrm{Cl}$ & $88.96(5)$ \\
\hline $\mathrm{N}(1)-\mathrm{C}(1)$ & $1.371(2)$ & $\mathrm{N}(3)-\mathrm{Ru}-\mathrm{Cl}$ & $89.427(13)$ \\
\hline $\mathrm{N}(1)-\mathrm{C}(3)$ & $1.427(2)$ & $\mathrm{C}(1)-\mathrm{Ru}-\mathrm{Cl} \# 1$ & $90.573(13)$ \\
\hline $\mathrm{N}(1)-\mathrm{C}(2)$ & $1.475(3)$ & $\mathrm{N}(2)-\mathrm{Ru}-\mathrm{Cl} \# 1$ & $88.96(5)$ \\
\hline $\mathrm{N}(2)-\mathrm{C}(12)$ & $1.353(3)$ & $\mathrm{N}(2) \# 1-\mathrm{Ru}-\mathrm{Cl} \# 1$ & $90.88(5)$ \\
\hline $\mathrm{N}(2)-\mathrm{C}(16)$ & $1.343(3)$ & N(3)-Ru-Cl\#1 & $89.427(13)$ \\
\hline $\mathrm{N}(3)-\mathrm{C}(17) \# 1$ & $1.344(2)$ & $\mathrm{Cl}-\mathrm{Ru}-\mathrm{Cl} \# 1$ & $178.85(3)$ \\
\hline $\mathrm{N}(3)-\mathrm{C}(17)$ & $1.344(2)$ & $\mathrm{C}(1)-\mathrm{N}(1)-\mathrm{C}(3)$ & $131.92(17)$ \\
\hline $\mathrm{C}(1)-\mathrm{N}(1) \# 1$ & $1.371(2)$ & $\mathrm{C}(1)-\mathrm{N}(1)-\mathrm{C}(2)$ & $113.84(18)$ \\
\hline $\mathrm{C}(2)-\mathrm{C}(2) \# 1$ & $1.479(5)$ & $\mathrm{C}(3)-\mathrm{N}(1)-\mathrm{C}(2)$ & $114.23(17)$ \\
\hline $\mathrm{C}(2)-\mathrm{H}(2 \mathrm{~A})$ & $0.90(3)$ & $\mathrm{C}(12)-\mathrm{N}(2)-\mathrm{C}(16)$ & $114.72(19)$ \\
\hline $\mathrm{C}(2)-\mathrm{H}(2 \mathrm{~B})$ & $0.95(2)$ & $\mathrm{C}(12)-\mathrm{N}(2)-\mathrm{Ru}$ & $119.76(14)$ \\
\hline $\mathrm{C}(3)-\mathrm{C}(4)$ & $1.391(3)$ & $\mathrm{C}(16)-\mathrm{N}(2)-\mathrm{Ru}$ & $124.28(15)$ \\
\hline$C(3)-C(8)$ & $1.399(3)$ & $\mathrm{C}(17) \# 1-\mathrm{N}(3)-\mathrm{C}(17)$ & $116.6(2)$ \\
\hline$C(4)-C(5)$ & $1.386(3)$ & $\mathrm{C}(17) \# 1-\mathrm{N}(3)-\mathrm{Ru}$ & $121.71(12)$ \\
\hline$C(4)-C(9)$ & $1.496(3)$ & $\mathrm{C}(17)-\mathrm{N}(3)-\mathrm{Ru}$ & $121.71(12)$ \\
\hline$C(5)-C(6)$ & $1.384(3)$ & $\mathrm{N}(1) \# 1-\mathrm{C}(1)-\mathrm{N}(1)$ & $103.9(2)$ \\
\hline $\mathrm{C}(5)-\mathrm{H}(5)$ & $0.92(2)$ & $\mathrm{N}(1) \# 1-\mathrm{C}(1)-\mathrm{Ru}$ & $128.03(11)$ \\
\hline$C(6)-C(7)$ & $1.379(3)$ & $\mathrm{N}(1)-\mathrm{C}(1)-\mathrm{Ru}$ & $128.03(11)$ \\
\hline$C(6)-C(10)$ & $1.508(3)$ & $\mathrm{N}(1)-\mathrm{C}(2)-\mathrm{C}(2) \# 1$ & $102.40(15)$ \\
\hline$C(7)-C(8)$ & $1.380(3)$ & $\mathrm{N}(1)-\mathrm{C}(2)-\mathrm{H}(2 \mathrm{~A})$ & $111.3(17)$ \\
\hline $\mathrm{C}(7)-\mathrm{H}(7)$ & $0.94(2)$ & $\mathrm{C}(2) \# 1-\mathrm{C}(2)-\mathrm{H}(2 \mathrm{~A})$ & $115.1(18)$ \\
\hline$C(8)-C(11)$ & $1.499(3)$ & $\mathrm{N}(1)-\mathrm{C}(2)-\mathrm{H}(2 \mathrm{~B})$ & $104.8(18)$ \\
\hline $\mathrm{C}(9)-\mathrm{H}(9 \mathrm{~A})$ & $0.96(2)$ & $\mathrm{C}(2) \# 1-\mathrm{C}(2)-\mathrm{H}(2 \mathrm{~B})$ & $114.8(17)$ \\
\hline $\mathrm{C}(9)-\mathrm{H}(9 \mathrm{~B})$ & $0.86(3)$ & $\mathrm{H}(2 \mathrm{~A})-\mathrm{C}(2)-\mathrm{H}(2 \mathrm{~B})$ & $108(2)$ \\
\hline $\mathrm{C}(9)-\mathrm{H}(9 \mathrm{C})$ & $0.97(3)$ & $C(4)-C(3)-C(8)$ & $121.16(19)$ \\
\hline $\mathrm{C}(10)-\mathrm{H}(10 \mathrm{~A})$ & $0.89(3)$ & $\mathrm{C}(4)-\mathrm{C}(3)-\mathrm{N}(1)$ & $120.50(19)$ \\
\hline $\mathrm{C}(10)-\mathrm{H}(10 \mathrm{~B})$ & $0.89(3)$ & $\mathrm{C}(8)-\mathrm{C}(3)-\mathrm{N}(1)$ & 117.76(19) \\
\hline $\mathrm{C}(10)-\mathrm{H}(10 \mathrm{C})$ & $0.98(4)$ & $C(5)-C(4)-C(3)$ & 117.99(19) \\
\hline $\mathrm{C}(11)-\mathrm{H}(11 \mathrm{~A})$ & $0.99(3)$ & $\mathrm{C}(5)-\mathrm{C}(4)-\mathrm{C}(9)$ & $120.7(2)$ \\
\hline $\mathrm{C}(11)-\mathrm{H}(11 \mathrm{~B})$ & $0.88(2)$ & $\mathrm{C}(3)-\mathrm{C}(4)-\mathrm{C}(9)$ & $121.3(2)$ \\
\hline $\mathrm{C}(11)-\mathrm{H}(11 \mathrm{C})$ & $0.93(2)$ & $\mathrm{C}(4)-\mathrm{C}(5)-\mathrm{C}(6)$ & $122.3(2)$ \\
\hline$C(12)-C(13)$ & $1.374(3)$ & $\mathrm{C}(4)-\mathrm{C}(5)-\mathrm{H}(5)$ & $119.8(13)$ \\
\hline $\mathrm{C}(12)-\mathrm{H}(12)$ & $1.02(2)$ & $\mathrm{C}(6)-\mathrm{C}(5)-\mathrm{H}(5)$ & $117.8(13)$ \\
\hline$C(13)-C(14)$ & $1.370(3)$ & $C(7)-C(6)-C(5)$ & $117.8(2)$ \\
\hline $\mathrm{C}(13)-\mathrm{H}(13)$ & $0.97(2)$ & $C(7)-C(6)-C(10)$ & $120.2(3)$ \\
\hline $\mathrm{C}(14)-\mathrm{C}(15)$ & $1.373(3)$ & $C(5)-C(6)-C(10)$ & $122.0(3)$ \\
\hline $\mathrm{C}(14)-\mathrm{H}(14)$ & $0.94(2)$ & $C(6)-C(7)-C(8)$ & $122.5(2)$ \\
\hline$C(15)-C(16)$ & $1.374(3)$ & $\mathrm{C}(6)-\mathrm{C}(7)-\mathrm{H}(7)$ & $118.7(14)$ \\
\hline $\mathrm{C}(15)-\mathrm{H}(15)$ & $0.929(19)$ & $\mathrm{C}(8)-\mathrm{C}(7)-\mathrm{H}(7)$ & $118.8(14)$ \\
\hline $\mathrm{C}(16)-\mathrm{H}(16)$ & $0.909(19)$ & $\mathrm{C}(7)-\mathrm{C}(8)-\mathrm{C}(3)$ & $118.1(2)$ \\
\hline $\mathrm{C}(17)-\mathrm{C}(18)$ & $1.377(3)$ & $\mathrm{C}(7)-\mathrm{C}(8)-\mathrm{C}(11)$ & $121.8(2)$ \\
\hline $\mathrm{C}(17)-\mathrm{H}(17)$ & $0.917(17)$ & $\mathrm{C}(3)-\mathrm{C}(8)-\mathrm{C}(11)$ & $120.1(2)$ \\
\hline $\mathrm{C}(18)-\mathrm{C}(19)$ & $1.372(3)$ & $\mathrm{C}(4)-\mathrm{C}(9)-\mathrm{H}(9 \mathrm{~A})$ & $111.6(13)$ \\
\hline $\mathrm{C}(18)-\mathrm{H}(18)$ & $0.911(18)$ & $\mathrm{C}(4)-\mathrm{C}(9)-\mathrm{H}(9 \mathrm{~B})$ & $110.5(19)$ \\
\hline C(19)-C(18)\#1 & $1.372(3)$ & H(9A)-C(9)-H(9B) & $110(2)$ \\
\hline \multirow[t]{2}{*}{$\mathrm{C}(19)-\mathrm{H}(19)$} & $0.88(3)$ & $\mathrm{C}(4)-\mathrm{C}(9)-\mathrm{H}(9 \mathrm{C})$ & $111.5(17)$ \\
\hline & & $\mathrm{H}(9 \mathrm{~A})-\mathrm{C}(9)-\mathrm{H}(9 \mathrm{C})$ & $109(2)$ \\
\hline $\mathrm{C}(1)-\mathrm{Ru}-\mathrm{N}(2)$ & $97.92(4)$ & $\mathrm{H}(9 \mathrm{~B})-\mathrm{C}(9)-\mathrm{H}(9 \mathrm{C})$ & $104(2)$ \\
\hline $\mathrm{C}(1)-\mathrm{Ru}-\mathrm{N}(2) \# 1$ & $97.92(4)$ & $\mathrm{C}(6)-\mathrm{C}(10)-\mathrm{H}(10 \mathrm{~A})$ & $108.7(18)$ \\
\hline $\mathrm{N}(2)-\mathrm{Ru}-\mathrm{N}(2) \# 1$ & $164.16(8)$ & $\mathrm{C}(6)-\mathrm{C}(10)-\mathrm{H}(10 \mathrm{~B})$ & $113(2)$ \\
\hline
\end{tabular}




$\begin{array}{llll}\mathrm{H}(10 \mathrm{~A})-\mathrm{C}(10)-\mathrm{H}(10 \mathrm{~B}) & 106(3) & \mathrm{C}(15)-\mathrm{C}(14)-\mathrm{H}(14) & 119.5(13) \\ \mathrm{C}(6)-\mathrm{C}(10)-\mathrm{H}(10 \mathrm{C}) & 114(2) & \mathrm{C}(13)-\mathrm{C}(14)-\mathrm{H}(14) & 122.4(13) \\ \mathrm{H}(10 \mathrm{~A})-\mathrm{C}(10)-\mathrm{H}(10 \mathrm{C}) & 112(3) & \mathrm{C}(16)-\mathrm{C}(15)-\mathrm{C}(14) & 119.0(2) \\ \mathrm{H}(10 \mathrm{~B})-\mathrm{C}(10)-\mathrm{H}(10 \mathrm{C}) & 102(3) & \mathrm{C}(16)-\mathrm{C}(15)-\mathrm{H}(15) & 121.4(12) \\ \mathrm{C}(8)-\mathrm{C}(11)-\mathrm{H}(11 \mathrm{~A}) & 112.1(19) & \mathrm{C}(14)-\mathrm{C}(15)-\mathrm{H}(15) & 119.6(12) \\ \mathrm{C}(8)-\mathrm{C}(11)-\mathrm{H}(11 \mathrm{~B}) & 109.2(18) & \mathrm{N}(2)-\mathrm{C}(16)-\mathrm{C}(15) & 124.7(2) \\ \mathrm{H}(11 \mathrm{~A})-\mathrm{C}(11)-\mathrm{H}(11 \mathrm{~B}) & 108(3) & \mathrm{N}(2)-\mathrm{C}(16)-\mathrm{H}(16) & 115.3(12) \\ \mathrm{C}(8)-\mathrm{C}(11)-\mathrm{H}(11 \mathrm{C}) & 113.4(15) & \mathrm{C}(15)-\mathrm{C}(16)-\mathrm{H}(16) & 120.1(12) \\ \mathrm{H}(11 \mathrm{~A})-\mathrm{C}(11)-\mathrm{H}(11 \mathrm{C}) & 105(2) & \mathrm{N}(3)-\mathrm{C}(17)-\mathrm{C}(18) & 123.2(2) \\ \mathrm{H}(11 \mathrm{~B})-\mathrm{C}(11)-\mathrm{H}(11 \mathrm{C}) & 110(2) & \mathrm{N}(3)-\mathrm{C}(17)-\mathrm{H}(17) & 116.6(11) \\ \mathrm{N}(2)-\mathrm{C}(12)-\mathrm{C}(13) & 124.0(2) & \mathrm{C}(18)-\mathrm{C}(17)-\mathrm{H}(17) & 120.2(11) \\ \mathrm{N}(2)-\mathrm{C}(12)-\mathrm{H}(12) & 113.9(13) & \mathrm{C}(19)-\mathrm{C}(18)-\mathrm{C}(17) & 119.3(2) \\ \mathrm{C}(13)-\mathrm{C}(12)-\mathrm{H}(12) & 122.1(13) & \mathrm{C}(19)-\mathrm{C}(18)-\mathrm{H}(18) & 122.2(12) \\ \mathrm{C}(12)-\mathrm{C}(13)-\mathrm{C}(14) & 119.5(2) & \mathrm{C}(17)-\mathrm{C}(18)-\mathrm{H}(18) & 118.4(12) \\ \mathrm{C}(12)-\mathrm{C}(13)-\mathrm{H}(13) & 116.3(13) & \mathrm{C}(18) \# 1-\mathrm{C}(19)-\mathrm{C}(18) & 118.5(3) \\ \mathrm{C}(14)-\mathrm{C}(13)-\mathrm{H}(13) & 124.2(13) & \mathrm{C}(18) \# 1-\mathrm{C}(19)-\mathrm{H}(19) & 120.77(14) \\ \mathrm{C}(15)-\mathrm{C}(14)-\mathrm{C}(13) & 118.0(2) & \mathrm{C}(18)-\mathrm{C}(19)-\mathrm{H}(19) & 120.77(14) \\ & & & \end{array}$

Symmetry transformations used to generate equivalent atoms:

$\# 1-\mathrm{x}+2, \mathrm{y},-\mathrm{z}+1 / 2$ 
Table S.19. Anisotropic displacement parameters $\left(\AA^{2} x 1^{4}\right)$ for 25 (CCDC 177531). The anisotropic displacement factor exponent takes the form: $-2 \pi^{2}\left[h^{2} a^{* 2} U^{11}+\ldots+2 h k^{*} b^{*} U^{12}\right]$

\begin{tabular}{lcccccc}
\hline & $\mathrm{U}^{11}$ & $\mathrm{U}^{22}$ & $\mathrm{U}^{33}$ & $\mathrm{U}^{23}$ & $\mathrm{U}^{13}$ & $\mathrm{U}^{12}$ \\
\hline $\mathrm{Ru}$ & $106(1)$ & $119(1)$ & $131(1)$ & 0 & $4(1)$ & 0 \\
$\mathrm{Cl}$ & $129(2)$ & $200(3)$ & $233(3)$ & $30(2)$ & $28(2)$ & $14(2)$ \\
$\mathrm{N}(1)$ & $550(14)$ & $111(8)$ & $136(9)$ & $-13(7)$ & $-42(9)$ & $35(9)$ \\
$\mathrm{N}(2)$ & $173(9)$ & $92(9)$ & $226(10)$ & $18(7)$ & $7(8)$ & $5(7)$ \\
$\mathrm{N}(3)$ & $105(10)$ & $126(11)$ & $171(11)$ & 0 & $-42(12)$ & 0 \\
$\mathrm{C}(1)$ & $149(13)$ & $191(15)$ & $150(13)$ & 0 & $13(15)$ & 0 \\
$\mathrm{C}(2)$ & $1350(40)$ & $160(13)$ & $228(14)$ & $-24(11)$ & $-170(20)$ & $88(19)$ \\
$\mathrm{C}(3)$ & $302(13)$ & $101(11)$ & $152(11)$ & $25(8)$ & $-23(9)$ & $24(8)$ \\
$\mathrm{C}(4)$ & $235(12)$ & $138(11)$ & $257(12)$ & $57(10)$ & $34(9)$ & $71(10)$ \\
$\mathrm{C}(5)$ & $237(13)$ & $169(11)$ & $341(14)$ & $22(11)$ & $-134(10)$ & $17(11)$ \\
$\mathrm{C}(6)$ & $434(16)$ & $206(13)$ & $169(12)$ & $29(10)$ & $-45(10)$ & $38(11)$ \\
$\mathrm{C}(7)$ & $308(15)$ & $282(14)$ & $243(13)$ & $69(10)$ & $116(10)$ & $16(10)$ \\
$\mathrm{C}(8)$ & $231(12)$ & $181(12)$ & $239(13)$ & $69(10)$ & $-26(10)$ & $-20(9)$ \\
$\mathrm{C}(9)$ & $321(16)$ & $351(16)$ & $493(18)$ & $204(16)$ & $183(13)$ & $163(15)$ \\
$\mathrm{C}(10)$ & $920(30)$ & $430(20)$ & $229(15)$ & $-24(16)$ & $-156(17)$ & $40(20)$ \\
$\mathrm{C}(11)$ & $299(17)$ & $406(19)$ & $580(20)$ & $197(17)$ & $-112(16)$ & $-88(14)$ \\
$\mathrm{C}(12)$ & $296(14)$ & $154(12)$ & $277(14)$ & $34(10)$ & $-71(11)$ & $-19(10)$ \\
$\mathrm{C}(13)$ & $373(15)$ & $192(12)$ & $309(15)$ & $36(10)$ & $-125(12)$ & $-42(11)$ \\
$\mathrm{C}(14)$ & $507(18)$ & $222(13)$ & $239(15)$ & $-46(11)$ & $-143(13)$ & $71(12)$ \\
$\mathrm{C}(15)$ & $399(17)$ & $261(13)$ & $212(13)$ & $-10(10)$ & $12(12)$ & $88(12)$ \\
$\mathrm{C}(16)$ & $304(14)$ & $171(12)$ & $218(11)$ & $-2(8)$ & $-12(11)$ & $42(12)$ \\
$\mathrm{C}(17)$ & $117(11)$ & $197(12)$ & $192(12)$ & $7(10)$ & $-22(9)$ & $0(9)$ \\
$\mathrm{C}(18)$ & $146(11)$ & $202(12)$ & $263(12)$ & $-62(11)$ & $-35(10)$ & $28(10)$ \\
$\mathrm{C}(19)$ & $181(15)$ & $116(14)$ & $346(17)$ & 0 & $-98(17)$ & 0 \\
& & & & & & \\
\hline & & & & & & \\
& & & & & \\
\end{tabular}


Table S.20. Hydrogen coordinates $\left(\times 10^{4}\right)$ and isotropic displacement parameters $\left(\AA^{2} \times 10^{3}\right)$ for 25 (CCDC 177531).

\begin{tabular}{|c|c|c|c|c|}
\hline & $\mathrm{X}$ & $\mathrm{y}$ & $\mathrm{z}$ & $\mathrm{U}_{\text {iso }}$ \\
\hline $\mathrm{H}(2 \mathrm{~A})$ & $10080(20)$ & $5260(20)$ & $1902(12)$ & $54(8)$ \\
\hline $\mathrm{H}(2 \mathrm{~B})$ & $8900(20)$ & $5030(20)$ & $2185(12)$ & $63(11)$ \\
\hline $\mathrm{H}(5)$ & $7582(18)$ & $3213(15)$ & $332(9)$ & $27(6)$ \\
\hline $\mathrm{H}(7)$ & 10978(19) & $3783(15)$ & $44(10)$ & $33(7)$ \\
\hline $\mathrm{H}(9 \mathrm{~A})$ & $7607(18)$ & $2928(16)$ & 1914(10) & $29(6)$ \\
\hline $\mathrm{H}(9 \mathrm{~B})$ & $7210(20)$ & $3930(20)$ & $1693(13)$ & $68(10)$ \\
\hline $\mathrm{H}(9 \mathrm{C})$ & $6740(30)$ & $3090(20)$ & $1352(13)$ & $67(10)$ \\
\hline $\mathrm{H}(10 \mathrm{~A})$ & $8320(20)$ & $3410(20)$ & $-703(12)$ & $57(10)$ \\
\hline $\mathrm{H}(10 \mathrm{~B})$ & $9320(30)$ & $2780(30)$ & $-759(14)$ & $81(12)$ \\
\hline $\mathrm{H}(10 \mathrm{C})$ & $9550(30)$ & $3840(30)$ & $-866(17)$ & $115(15)$ \\
\hline $\mathrm{H}(11 \mathrm{~A})$ & $11800(30)$ & $4650(20)$ & $1402(14)$ & $88(12)$ \\
\hline $\mathrm{H}(11 \mathrm{~B})$ & $12270(20)$ & $3950(20)$ & $908(12)$ & $50(9)$ \\
\hline $\mathrm{H}(11 \mathrm{C})$ & $11970(20)$ & $3544(18)$ & $1527(11)$ & $44(8)$ \\
\hline $\mathrm{H}(12)$ & $7820(20)$ & $992(16)$ & $1843(11)$ & $43(7)$ \\
\hline $\mathrm{H}(13)$ & $7176(19)$ & $426(16)$ & $865(10)$ & $36(7)$ \\
\hline $\mathrm{H}(14)$ & $8486(18)$ & $552(15)$ & $-22(10)$ & $27(6)$ \\
\hline $\mathrm{H}(15)$ & $10349(17)$ & $1169(15)$ & $145(9)$ & $20(6)$ \\
\hline $\mathrm{H}(16)$ & $10857(17)$ & $1721(14)$ & 1133(8) & $14(5)$ \\
\hline $\mathrm{H}(17)$ & $11027(15)$ & $-156(13)$ & 1786(8) & $9(5)$ \\
\hline $\mathrm{H}(18)$ & 11099(16) & $-1853(13)$ & 1775(9) & $12(5)$ \\
\hline $\mathrm{H}(19)$ & 10000 & $-2720(20)$ & 2500 & $19(7)$ \\
\hline
\end{tabular}

